\title{
Micro-geographic shift between negligible and actuarial senescence in a wild snake
}

\author{
Thomas Tully ${ }^{1,2}$, Jean-François Le Galliard ${ }^{1,3}$ \& Jean-Pierre Baron ${ }^{1}$
}

\section{Affiliations:}

1. Sorbonne Université, CNRS, Institute of ecology and environmental sciences, iEES-Paris, F-75005, Paris, France.

2. Sorbonne Université, INSPE, 10 rue Molitor, 75016 Paris, France

3. Ecole normale supérieure, PSL Research University, Département de biologie, CNRS, UMS 3194, Centre de recherche en écologie expérimentale et prédictive (CEREEP-Ecotron IleDeFrance), 78 rue du château, 77140 Saint-Pierre-lès-Nemours, France.

\section{Doi}

https://doi.org/10.1111/1365-2656.13317

\section{Orcid \& email:}

Thomas Tully <thomas.tully@sorbonne-universite.fr>

Le Galliard Jean-François <galliard@bio.ens.psl.eu> Jean-Pierre Baron <aldebertb@yahoo.fr>

\author{
Address correspondence to : \\ Thomas Tully, \\ Institut d'écologie et des sciences de l'en- \\ vironnement de Paris, \\ CNRS - UMR 7618, iEES Paris, \\ Sorbonne Université, \\ 4 Place de Jussieu, \\ Bâtiment 44-45, 2eme, Bureau 216, 75005 Paris, \\ France. \\ Tel. +33 144272668 Fax: +33 144273516
}

Short running title: Pace and shape of ageing in vipers.

Key words: ageing, life history trade-off, pace and shape, phenotypic plasticity, reproductive effort, survival.

Funding: This research has been partly supported by the Centre National de la Recherche Scientifique (CNRS) and by the ANR program 07-JCJC-0120 to J.-F. Le Galliard.

\section{Abstract}

1 While it has long been known that species have contrasted life expectancy (pace of mortality) and generation time (pace of reproduction), recent studies have also uncovered that the shape of adult age-trajectories of mortality and reproduction can vary remarkably among species along a continuum of senescence ranging from strong deterioration (senescence), insignificant deterioration (negligible senescence) to improvement with advancing age (negative senescence).

2 As for many long-lived ectotherms with asymptotic growth and increasing reproductive output with age, snakes are good candidates for negligible senescence to occur. Yet, intraspecific variation in the pace and shape of actuarial and reproductive senescence across wild populations of these species remains to be explored.

3 Here, we used 37 years of mark-recapture data in two nearby habitats inside a meadow viper Vipera ursinii population to quantify life expectancies, generation times and the shape of actuarial and reproductive senescence.

4 Female vipers maintained stable reproductive performances at old ages, even when accounting for the predicted increase of fertility with body size, providing evidence for negligible reproductive senescence in both habitats.

5 Males had a higher adult mortality and a shorter life expectancy on average than females and actuarial senescence shifted from negligible senescence in the optimal habitat to strong senescence in the sub-optimal habitat.

6 Overall, these results demonstrate that micro-geographic environmental variation can generate qualitative shifts in actuarial senescence patterns. This highlights that taking into account the within-species plasticity of age-dependent trajectories could prove useful in better understanding what determines the evolution of life history age-trajectories. 


\section{INTRODUCTION}

Senescence can be defined as the inexorable and progressive deterioration of an adult organism with advancing age. Senescence has been found to affect many organisms and was considered to be almost universal until recent comparative analysis uncovered its striking diversity across species, sexes and demographic traits (Shefferson, Jones, \& Salguero-Gómez, 2017; Blažek et al., 2017; Jones et al., 2014; Mallard, Farina, \& Tully, 2015; Hayward et al., 2015). This diversity includes differences in how fast the individuals age (i.e. the pace of ageing), and in how strongly they age (i.e. the shape of ageing) (Baudisch, 2011). This pace and shape framework can be used to study mortality (pace and shape of mortality, or of actuarial senescence, Baudisch, 2011; Wrycza, Missov, \& Baudisch, 2015) and reproduction (pace and shape of reproduction, Baudisch \& Stott, 2019). The pace of mortality (also called pace of life) depends on the mean mortality rate. It can be measured by the adult life expectancy: fast species or fast populations have a shorter life expectancy than slow ones. Similarly, the pace of reproduction can be measured from the generation time, defined as the age of a mother at the birth of an average child (Baudisch \& Stott, 2019). The shape of ageing quantifies whether and how much the mortality and/or reproduction change with age. Comparing the shape of ageing among species or among populations thus requires detailed analysis of age-specific life histories and standardised comparisons of survival and reproductive trajectories (Baudisch, 2011; Wrycza et al., 2015; Baudisch \& Stott, 2019).

Senescence occurs in a population when the adult mortality increases with advancing age (actuarial senescence) and/or when the reproduction decreases with age (reproductive senescence). Actually, senescence does not seem to be as inevitable as it was previously envisioned (Baudisch, 2008; Baudisch et al., 2013). Some species or some groups of individuals may escape senescence and display a flat or negligibly increasing mortality or fecundity rate with age (Vaupel, Baudisch, Dölling, A. Roach, \& Gampe, 2004; Finch, 1998; Finch, 2009; Baudisch et al., 2013; Vaupel, Carey, \& Christensen, 2003). Specific environmental conditions (e.g. dietary restriction or low temperature) and differences in demographic tactics early in life (e.g., reduced reproductive effort) can delay or slow down senescence so much that it becomes undetectable (Tatar, Chien, \& Priest, 2001; Bouwhuis, Charmantier, Verhulst, \& Sheldon, 2010; Kelly, Zieba, Buttemer, \& Hulbert, 2013): the adult mortality rate remains roughly constant. This pattern is called "negligible senescence" or "sustenance" (Finch, 1998), and can been seen when mortality and/or reproduction do not significantly change with age (Baudisch \& Stott, 2019). In some species, survival rate, fecundity and overall quality of individuals may even increase with age, causing negative senescence to occur (Baudisch et al., 2013; Jones et al., 2014).

Theoretical studies suggest that negligible actuarial senescence can evolve when the gain in residual reproductive value due to a higher investment in main- tenance outweighs the loss in current reproduction (Vaupel et al., 2004; Baudisch, 2008; Baudisch \& Vaupel, 2010). This condition is hypothesised to be met in species with indeterminate growth when extrinsic mortality decreases with body size and/or when fecundity increases with body size (Vaupel et al., 2004). For example, some clonal lineages of springtails, a group of hexapods with a continuous growth and whose fecundity increases with body size, can display very long periods of negligible senescence (Mallard et al., 2015). Squamate reptiles, and in particular snakes, are other good candidate species for negligible senescence because of their continuous growth during life and positive fitness effects of increased body size, especially for female reproductive output (Shine, 2003; Altwegg, Dummermuth, Anholt, \& Flatt, 2005; Forsman, 1997; Bronikowski, 2008). Unfortunately, exact data about the pace and shape of ageing are extremely limited in squamate reptiles for which long-term longitudinal studies of marked individuals are rare (Nussey, Froy, Lemaitre, Gaillard, \& Austad, 2013; Sparkman, Arnold, \& Bronikowski, 2007; Massot et al., 2011). Several authors have explored the pace of mortality in reptiles (Stark, Tamar, Itescu, Feldman, \& Meiri, 2018 ), but this provides no information on the shape of mortality or reproduction (Bronikowski \& Flatt, 2010). In the western terrestrial garter snake, Thamnophis elegans, a unique longitudinal study suggests weak reproductive senescence and no actuarial senescence across a range of slow and fast life histories (Sparkman et al., 2007).

In addition, environmental variation in the shape of mortality has not been investigated so far in wild populations of reptiles. Differences in environmental conditions (e.g., the quantity and quality of dietary resources) across populations may influence the proximate mechanisms underlying actuarial senescence (Nussey et al., 2013). Furthermore, the realisation of age-specific mortality factors may vary across environments, which can ultimately change selective pressures, and in turn, modify life-history strategies and the shape of their optimal age-trajectories (Wensink, Caswell, \& Baudisch, 2017). This should cause geographic variation in the occurrence, onset and sharpness of actuarial senescence - addressed by the shape of mortality measure - across populations and groups of individuals according to environmental conditions (Reichard, 2016). Interpopulation comparisons indicate that climate conditions (Hassall et al., 2016; Blažek et al., 2017), habitat features (Holand et al., 2016), resource competition (Nussey, Kruuk, Morris, \& Clutton-Brock, 2007) or captive conditions (Lemaître, Gaillard, Lackey, Clauss, \& Müller, 2013) can shift actuarial senescence from negligible to positive. Others have shown no significant change in the shape of mortality despite huge differences in the pace of mortality due to variation in extrinsic mortality (Reznick, Bryant, Roff, Ghalambor, \& Ghalambor, 2004; Morbey, Brassil, \& Hendry, 2005; Bronikowski et al., 2002) or huge differences in growth rate (Sparkman et al., 2007). It remains also unknown whether geographic patterns of actuarial senescence are similar in males and females. Thus, more comparisons are needed to understand the drivers of intraspecific variation in the 
shape and pace of mortality (Reichard, 2016).

We used field observations gathered during 37 years in a population of individually-marked meadow vipers (Vipera ursinii ursinii, Bonaparte, 1835) to measure the pace of mortality and of female reproduction (pace of ageing) and to study the effect of old age on mortality and reproduction (shape of ageing). The field site was divided into two contiguous habitats including a north facing and mesophilic hillside protected from human disturbance (habitat A), and a south facing and xerophilic hillside more exposed to human disturbance (habitat B, Supporting information 1, Figure S1). Previous studies have shown that the meadow viper has a slow life history with continuous growth, delayed sexual maturation at the age of 3-6 years, biennial capital breeding at adulthood, and increased reproductive output with body size (Baron, Le Galliard, Tully, \& Ferrière, 2010a; Baron, Tully, \& Le Galliard, 2010b; Baron, Galliard, Ferrière, \& Tully, 2013). Vipers living in the more xerophilic and disturbed habitat grow slower but invest similarly into reproduction than vipers from the mesophilic and less disturbed habitat (Baron et al., 2010b).

The quantification of the pace of mortality and the analysis of the age-specific survival and reproductive profiles from the two nearby habitats enabled us to test three related predictions. First, we anticipated differences in the pace of mortality between sexes with a shorter average life expectancy in males than in females (prediction 1). In the meadow viper, males should have a higher mean adult mortality than females given the increased activity of male vipers in unfamiliar and potentially riskier environments during the mating season, which increases energy expenditure and exposure to predators (Baron, 1997). Second, following theoretical predictions by Vaupel et al. (2004) that species that grow indefinitely should escape senescence more frequently than those that are definite in their growth form, we predict that meadow vipers should exhibit actuarial negligible or negative senescence (prediction 2). As for other snakes, the meadow viper has indeed an indeterminate adult growth (Baron et al., 2010b; Baron et al., 2010a) and its fecundity increases significantly with female body size (Baron, 1997). Third, given the reported pattern of slower body growth but similar reproductive effort for females from the sub-optimal habitat $B$, we further predicted that there could be micro-geographic variation in the pace and/or the shape of mortality (prediction 3). First, the pace of mortality could be faster in the sub-optimal habitat. Second, a faster decline in reproduction and/or survival with age might occur in the sub-optimal habitat. This is because, for example, the allocation trade-off of energetic resources between maintenance (and thus survival at old age) and reproduction may become stronger in a more challenging and stressful environment (Reichard, 2016)

\section{StUdy SPECIES AND METHOdS}

\section{(a) Study species and site}

The meadow viper inhabits open and dry calcareous grasslands between 900 and $2200 \mathrm{~m}$ elevation in Southern Europe, where it is a vulnerable species
(Joger et al., 2009). This study was conducted in one population located in South-Eastern France (Mont Serein, ca. $1430 \mathrm{~m}$ a.s.I., $\left.44^{\circ} 18^{\prime} \mathrm{N}, 5^{\circ} 26^{\prime} \mathrm{E}\right)$. This population is relatively small (ca. $100 \mathrm{ha}$ ) and is isolated from the nearest populations $50 \mathrm{~km}$ away by inhospitable habitats. A study area of four ha inside this population has been continuously monitored since 1979 (Baron, 1997). The study area was divided in two contiguous study sites of ca. 2 ha each that differ mainly for their habitat and orientation: a north facing and mesophilic hillside (habitat A), and a south facing and xerophilic hillside (habitat B, Supporting Information 1). To compare the climatic conditions of the two habitats, three data loggers (thermochron iButton Maxim Integrated, San Jose, CA) were hidden in juniper tufts to record shade temperature every hour and three other loggers were buried in $\sim 30 \mathrm{~cm}$ depth holes to record below-ground temperature in each habitat between 2008 and 2017. Relative humidity in the shade of juniper tufts was also recorded during the active season in 2008. Air temperature and relative humidity records in the two habitats showed that on average habitat $A$ is colder and wetter than habitat B (see Supporting Information 1 and Figure S2 for details).

\section{(b) Collection of life history data}

The fieldwork started in 1979 and stopped in August 2016 (37 years). Capture sessions were typically conducted by one to three persons during two-weeks twice a year (74 different capture sessions). Each year, a first capture session was done in May during the mating season and before ovulation and a second capture session was done before the end of gestation in late August or early September (Baron, 1997). All animals located from a distance by sight were captured and transported to a laboratory for the measurement of body size (snout-vent length, SVL to the nearest $\mathrm{mm}$ ) and body mass to the nearest dg. Vipers were individually marked upon their first capture by scale clipping ( $\mathrm{N}=1042$ marked individuals) and sexual maturity and reproductive status (non-reproductive, reproductive, pregnant or postpregnant) of each female (529 females) was evaluated. Abdominal cavity was palpated to count ova each year during the second capture session and obtain accurate estimates of the total litter size (Baron et al., 2013). Captured animals were returned to the field at their exact capture location in the evening

In 1983-1988 and from 1994 onwards, pregnant females were kept in the laboratory until parturition to obtain reproductive data $(\mathrm{N}=498$ offspring, $\mathrm{N}=161$ litters, 28 years). Pregnant females were maintained in individual boxes $(350 \times 180 \times 210 \mathrm{~mm})$ provided with a shelter, damp soil, free access to water and a heat source enabling thermoregulation. The body mass of females was measured daily to obtain accurate data on total mass loss during parturition and post-parturition body mass. We also recorded the parturition date and counted the number of undeveloped ova, dead embryo, fully developed but stillborn embryo and healthy offspring to calculate the total litter size and litter success (i.e., proportion of healthy embryo in the total litter). On average, females were kept 13.2 days ( $\pm 8.9 \mathrm{SD}$ ) in the laboratory prior to giving birth. Offspring born in the laborat- 
ory were measured for their body mass and SVL at birth, and sexed according to the number of subcaudal scales (Baron, 1997). Mothers were later released with their offspring at the last capture location prior to hibernation on average 11 days ( $\pm 6.96 \mathrm{SD}$ ) after parturition.

\section{(c) Study variables and statistical models}

\section{(i) Estimating the age of the individuals}

We used a cross-sectional approach to quantify demographic ageing in this population. The age of snakes was estimated at each capture as the time difference between the date of capture and the birth date, which was either measured directly or estimated indirectly (see below). Since the beginning of the study and until August 2016, 462 snakes born in the laboratory were marked individually and released in the field site and 74 were recaptured at least one time later in their life. The remaining captures included snakes first encountered and marked in the field but not born in the laboratory (542 individuals). For those snakes, we estimated their year of birth using their body length, year day of capture and body mass using growth trajectories of known age individuals born in the laboratory and a k-nearest neighbours classification algorithm (Baron et al., $2010 b)$. This was possible with a high confidence only for individuals that were relatively small when they were first captured in the field (zero to three years old sub-adults) (Baron et al., 2010b). The calibration of this method on 200 individuals of known age showed that not more than $5 \%$ of the records were assigned an erroneous age and that the error was not higher than one year. Thus, we are confident that errors in age estimates are unlikely to affect our analyses.

Since we collected data in spring and in summer during about two or three weeks each year, a rough measurement of the age of the individuals in number of years was not sufficiently precise to distinguish between the two field sessions each year. We thus decided to calculate the "true" age in decimals of years. To do so, we used the median parturition date of the year (average of 5.7 records per year) or median parturition date of the study as a reference birth date for vipers not born in the laboratory. Stable parturition dates about the means ( $N=161$, day 251 , 6th of October) suggest that this metric is not biasing the results (Supporting Information 2). Thus, an age could be attributed to $58 \%$ of the marked vipers (605 individuals). On average $34 \%$ of the vipers captured, recaptured or observed in the field were of know age ( $N=623$ over 1833 observations). As expected, the proportion of individuals of known age captured in the field increased with time during the 37 years period (Supporting Information 3).

\section{(ii) The pace and shape of mortality}

Quantifying age-dependent mortality rates in wild populations is challenging because traditional methods restrict the analysis to individuals of known age, which make up only a small part of the observations. This can be problematic since it reduces the power to estimate accurately the capture probabilities and since it can hide age-pattern mortality later in life, when understanding the mortality at old age is fundamental in senescence research. To overcome these limitations, we used a method recently developed for wild populations (Colchero \& Clark, 2012) and implemented in the BaSTA statistical package (Colchero, Jones, \& Rebke, 2012). This method uses a Bayesian framework to analyse mark recapture records in order to estimate the agespecific survival rates from all capture-recapture records, including individual records where we do not know when the individual was born or died.

The BaSTA package allows to fit different functional models to the age-mortality trajectories including an exponential model with constant mortality, and three mortality models that enable mortality to vary with age according do different parametric functions, namely the Gompertz, Weibull or Logistic functions (Colchero et al., 2012). This package enables also to change the shape of these three functions using either default shapes or more complex shapes such as the Makeham and bathtub shapes. Thus, a total of ten shapes using between one and six parameters can be fitted to the data and compared. The BaSTA package further allows taking into account covariates. Here, we compared models with no covariate with models including as categorical covariates either a sex effect (males versus females), a habitat effect (habitat $A$ versus $B$ ), an additive effect of sex and habitat and an interaction between sex and habitat. This method allows conditioning the analysis to survival after a minimum age. We used this possibility to focus on models that excluded from the analysis snakes younger than two years old since young vipers are elusive and juvenile survival can vary dramatically between years (Baron et al., 2010a). Eventually, we run a total of 50 models and used the deviance information criterion (DIC) to compare model fit and rank them (see Supporting Information 4 for details). Models with the lowest DIC values should provide the best fits (Table 1).

We then used the model estimates to predict the mortality trajectories of males and females in each habitat (four groups, Figure 1) and quantify the pace and shape of mortality following method in Baudisch (2011). From the predicted mortality trajectories, we calculated the mean life expectancy of each group, expressed as the number of years of life for individuals that lived at least two years thus excluding juvenile survival. We used this life expectancy as a quantitative measure of the pace of mortality (called pace of life in Baudisch, 2011).

Table 1: The effect of age, sex and habitat on adult mortality rates. The ten best mortality models fitted for Vipera ursinii ordered by decreasing values of deviance information criterion (DIC). The best models (with the lowest DIC) show that the effect of age on mortality varies between habitats and sexes. See the Supporting Information 4 for detailed information on the 50 models adjusted to the data. The adjusted mortality trajectories from the 6 best models are plotted in Figure S7.

\begin{tabular}{|l|l|l|l|l|}
\hline $\begin{array}{l}\text { Mod } \\
\text { el N }\end{array}$ & $\begin{array}{l}\text { Mortality } \\
\text { function }\end{array}$ & Shape & $\begin{array}{l}\text { Categorical } \\
\text { covariates }\end{array}$ & DIC \\
\hline 50 & Gompertz & simple & Habitat (A, B) & 8209.1 \\
\hline
\end{tabular}




\begin{tabular}{|l|l|l|l|l|}
\hline 30 & Weibull & bathtub & $\begin{array}{l}\text { Sex*Habitat (FA, } \\
\text { FB, MA, MB) }\end{array}$ & 8225.4 \\
\hline 20 & Weibull & simple & Sex (F,M) & 8278.5 \\
\hline 29 & Weibull & Makeham & $\begin{array}{l}\text { Sex*Habitat (FA, } \\
\text { FB, MA, MB) }\end{array}$ & 8391.4 \\
\hline 49 & Logistic & simple & Habitat (A, B) & 8393.3 \\
\hline 40 & Gompertz & simple & $\begin{array}{l}\text { Sex+Habitat (FA, } \\
\text { MA, B) }\end{array}$ & 8428.9 \\
\hline 48 & Logistic & Makeham & Habitat (A, B) & 8430.9 \\
\hline 47 & Weibull & Makeham & Habitat (A, B) & 8456.3 \\
\hline 28 & Logistic & bathtub & $\begin{array}{l}\text { Sex*Habitat (FA, } \\
\text { FB, MA, MB) }\end{array}$ & 8479.0 \\
\hline
\end{tabular}

\begin{tabular}{|l|l|l|l|}
\hline 19 & Gompertz & simple & Sex $(F, M)$ \\
\hline
\end{tabular}

8488.3

We further visualised the shape of the mortality trajectories from time-standardised age pattern of mortality (Baudisch, 2011). To do so, we standardised both the age and the predicted mean and confidence intervals of the mortality curves of each group. The standardised age $x_{s}$, is given by $x_{s}=(x-2) /(L-2)$ where $x$ is the age and $L$ the life expectancy. We removed 2 to compute the age and longevity from two years since we only consider individuals that survived at least two years. The standardised mortality is given by the non-standardised mortality times the life expectancy $L$ of the group since mortality depends inversely on units of time.

A

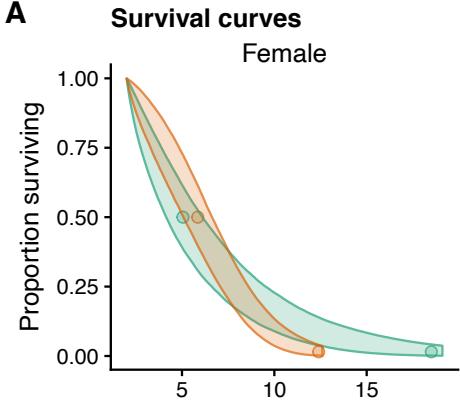

C

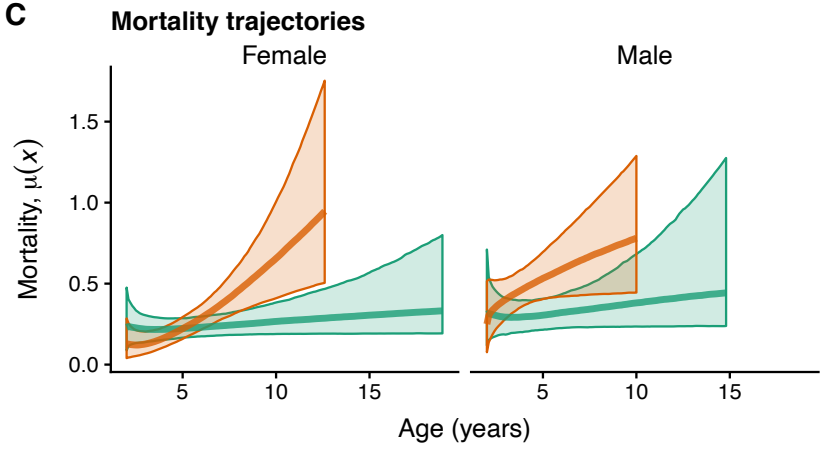

E

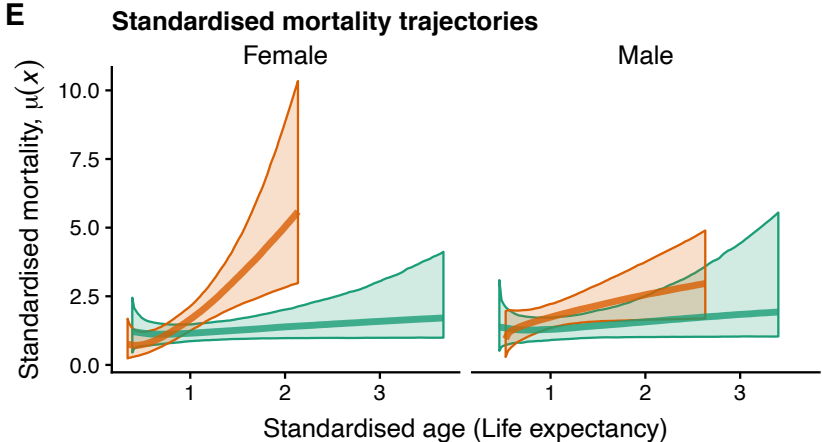

B

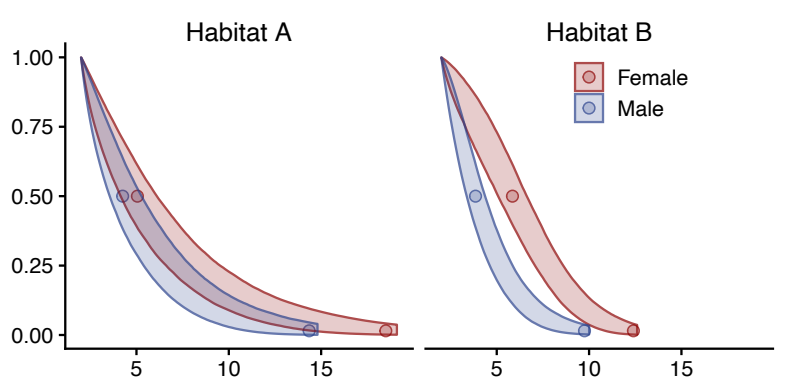

D

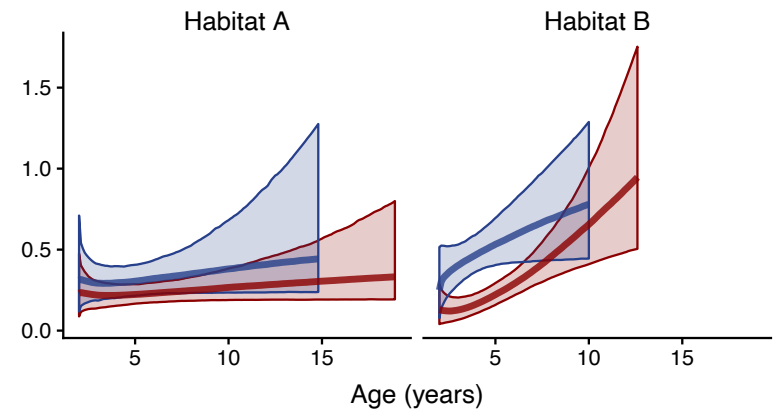

$\mathbf{F}$

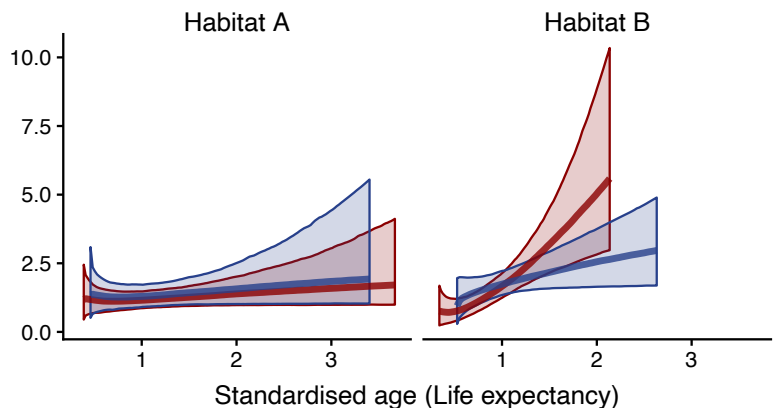

Figure 1: Survival curves and mortality age-trajectories from the second-best fitting model (model 30 in Table 1). This model corresponds to a bathtub Weibull function with fused covariate structure, which means that the categorical covariates (sex * habitat) are included as linear functions of the survival parameters (like in generalised linear models). Mortality is estimated from age 2, the first year of life being discarded from the analysis, and plotted separately for each sex and habitat with their $95 \%$ confidence intervals. The panels A and $\mathrm{B}$ represent the estimated female and male survival curves in the two habitats. The dots represent the predicted adult life expectancies (age when $50 \%$ of the adults - > 2 years olds - are dead) and the maximum lifespans (age when $99 \%$ of the individuals are dead) for the four groups of vipers. The female maximum lifespans are used to estimate the potential reproducing period in each habitat (Supporting information 6). The panels $C$ and $D$ display the raw mortality trajectories while the panels $E$ and $F$ represent the standardised mortality trajectories (mortality * life expectancies) against standardised age (age / life expectancies), which is required to compare the shape of ageing. Thus, age is measured as a unit of life expectancy (estimated 
life expectancy of individuals living at least 2 years, using the mortality trajectories, cf. dots in panels A, B). The left panels $(A, C, E)$ are made to make comparison of the two habitats for each sex easier while the panels on the right $(B, D, F)$ enable easy comparison of the two sexes in each habitat. The adult males suffer on average from a higher mortality than the females. Senescence is negligible in habitat $A$ for both sexes while mortality increases with age in habitat $\mathrm{B}$. The standardised trajectories make it even more obvious that the intensity of senescence of females is dramatically increased in the hash habitat (B) while this effect is less pronounced for males.

\section{(iii) The pace and shape of reproduction}

We first performed statistical analyses of individual reproduction histories in females controlling for differences in body size to test whether reproductive traits change while females get older irrespective of their size (Supporting information 5). Indeed, body size influences positively reproductive output independently from age in many reptiles (Massot et al., 2011). More specifically, we examined two traits describing the female investment into reproduction: the fecundity (number of eggs, Table S2, model C) and the reproductive investment (litter mass, Table S2, D) of reproductive females. We also examined the maternal effects on three offspring traits (Table S3): the newborn mass (model $E$ ), newborn condition $(F)$ and litter success $(G)$. We finally searched for any interactive effects of female age and habitat on female postpartum condition $(\mathrm{H})$. Newborn mass and condition influence the future growth and survival of juveniles and these are thus relevant quality traits in offspring (Baron et al., 2010a). We analysed reproductive traits with either Gaussian linear models (for reproductive investment, newborn mass and condition), positive Poisson models (fecundity) or binomial models (for litter success). Whenever needed, we used mixed models with viper's identity as a random factor to take into account the dependency between repeated observations from the same female (see details in Tables S2, S3).

Given that the vipers grow during their entire life, age and body length are correlated, even for old adults (Baron et al., 2010b). Thus, to study whether age has a direct effect on the reproductive traits, one has to control for the potentially confounding effect of size especially for traits like litter size or litter mass that increase with the female size. If it is not done, one can interpret an increase of fecundity with age as a sign of negligible senescence because the allometric positive relation between fecundity and size masks a negative effect of age on reproduction (Sparkman et al., 2007). To avoid these potential misinterpretations, we first run models with female length (and habitat) as covariates and we then replaced length with age only when no significant effect of female length was detected. When female length had a significant effect (see Tables S2, S3), we studied the effect of female age on size-corrected variables. For each observation, size-corrected value was calculated as the sum of the residuals of a model with female length as covariate plus the predicted value of this model for a "mean" mother (i.e., a female of the average snout vent length of $350 \mathrm{~mm}$ ). Thus, in the models exploring the effect of female's age on the female reproductive traits, we tested an effect of age after correction for differences in body length.

The pace and shape statistics of reproduction were then calculated following Baudisch \& Stott (Baudisch \& Stott, 2019). These authors suggest to measure the pace of reproduction as the mean age of the mothers at the birth of an average child, which corresponds to the generation time. We used the data collected on all the reproductive events of the females of known age to estimate this parameter (Supporting Information 3). Measuring the shape of reproduction is less straightforward and requires several steps to calculate a standardised, cumulative reproductive function (see Supporting information 6 and Figure S8 for details). We also report the reproduction (fecundity and reproductive investment) corrected for mother's body length as a function of standardised age in Supporting information 7 (Figure S9).

\section{Results}

\section{(a) Actuarial senescence}

Among the 50 different BaSTA mortality models compared with the DIC, models that assumed a mortality rate independent of age (Exponential models) were among the ones that had the poorest fit to the data while the best-fitting models were Weibull or Gompertz models allowing for continuously increasing mortality rates with age (Table 1 , see Supporting information 4 for details and figures on models). We also found that the DIC of the models improved when sex and/or habitat were included as covariates and that the two best models included habitat differences in actuarial senescence patterns (Table 1). This supports the idea that different groups of vipers have different mortality trajectories.

The mortality trajectories estimated by the secondbest model (model 30 ) included a bathtub Weibull shape with the two-way interaction between sex and habitat (see Table 1 and Figure 1). This model revealed that ageing patterns ranged from a continuously increasing mortality trajectory with age (positive senescence) to an age-independent flat mortality trajectory (negligible senescence) depending on sex and habitat. In habitat $A$, both sexes displayed a negligible senescence but males had a higher basal mortality rate than females (Figure 1). In habitat B, males also had higher mortality rate than females but both sexes suffered from senescence, especially females (Figure 1C, D). A similar qualitative difference between the two habitats was found in the first best model, which did not include sexual differences in mortality (see Figure S7). Thus, habitat A provided environmental conditions for senescence to become negligible even for individuals older than 10 years old in both sexes or, to some extent, more strongly in 
females than in males.

The pace and shape of mortality were calculated for each sex and habitat from the same model. On average, females had longer lifespans than males and the habitat $A$ bears older individuals than habitat $B$ (see Supporting Information 3 for data on age structure): females lived about one year longer ( 5.5 years) after two years old than males ( $\sim 4.05$ years) on average and their life expectancy was slightly longer in habitat $A$ (5.85 years) than in habitat $B$ (5.05 years, Figure S8A). The differences in mortality trajectories between sexes and habitats mentioned earlier remained qualitatively similar after a standardisation to reveal the shape of mortality (Figure 1 $\mathrm{E}, \mathrm{F}$ ).

\section{(b) Reproductive senescence}

Fecundity and litter mass increased with body length similarly in the two habitats and did not vary on average between habitats $(P<0.001$, Table $S 2$ models C1, D1; Figure 2A, C). Size-corrected fecundity and litter mass were not influenced by female age nor by habitat (Table S2 models C2, D2; Figure 2B, D and Figure S9A, B for standardised age). Newborn mass and condition were influenced by an interaction between female's length and habitat (Table S3 models $E 1, F 1$; Figure $3 A, C$ ). In habitat $A$, the mass at birth increased slightly with the female's length while the body condition at birth remained on average stable. In habitat $B$, the mass and condition of newborns at birth decreased slightly with the female's length (Table S3 models E2-3, F2-3; Figure 3A, C). After correcting for these effects of the female's length, we found no effect of the female's age on the newborn mass and a positive effect of age on newborn condition (Table S3 models E4, F4; Figure 3B, D). Note that the observed increase of newborn condition with mother's age was only due to the old females (>10 years old) in habitat $A$, which produced slightly more corpulent young (Table S3 model F5). The litter success was relatively high in both habitats $(77.5 \%)$, and did not depend on the mother's length and age (Table S3 models G1-2; Figure 4A). We found no sign of senescence or any effect of habitat on post-partum condition (Table S3 model H1; Figure 4B).
A
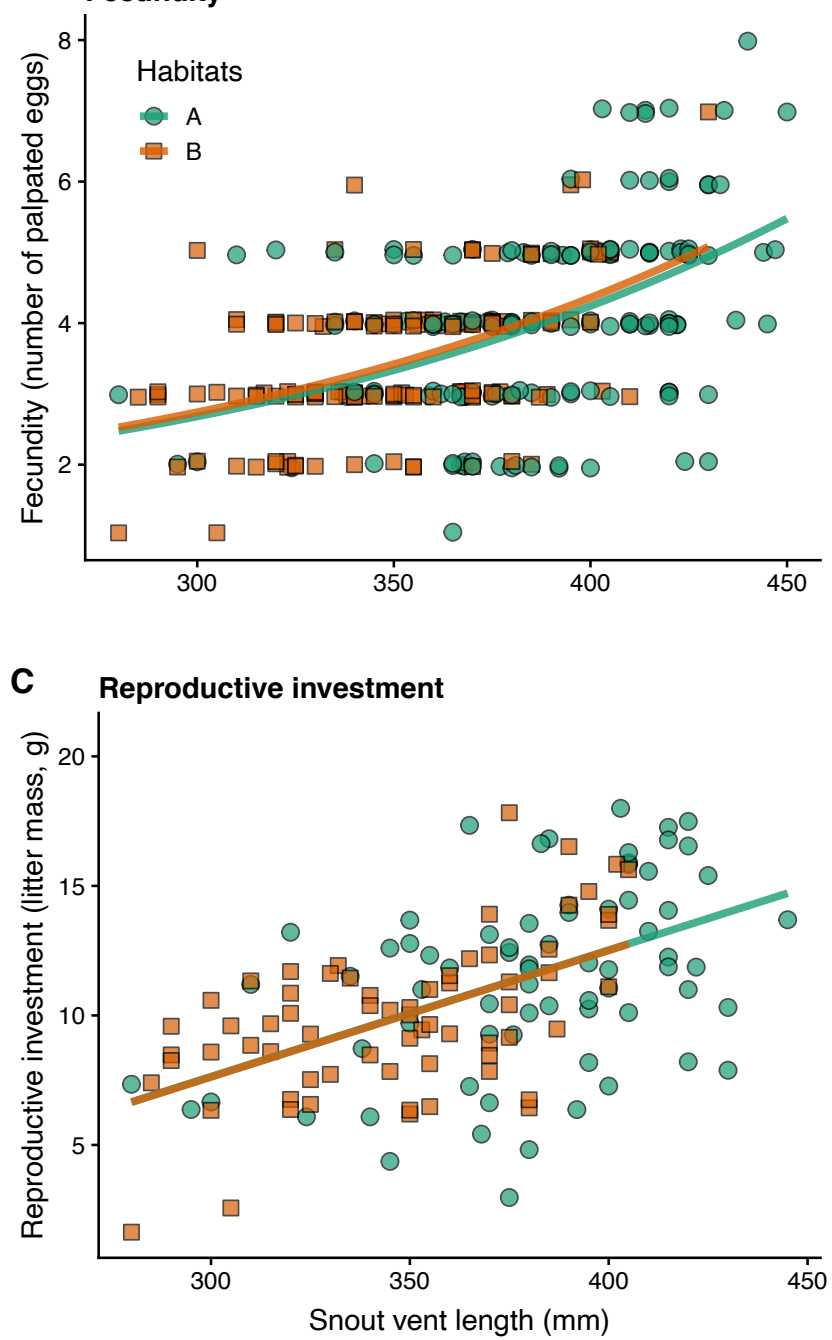

B

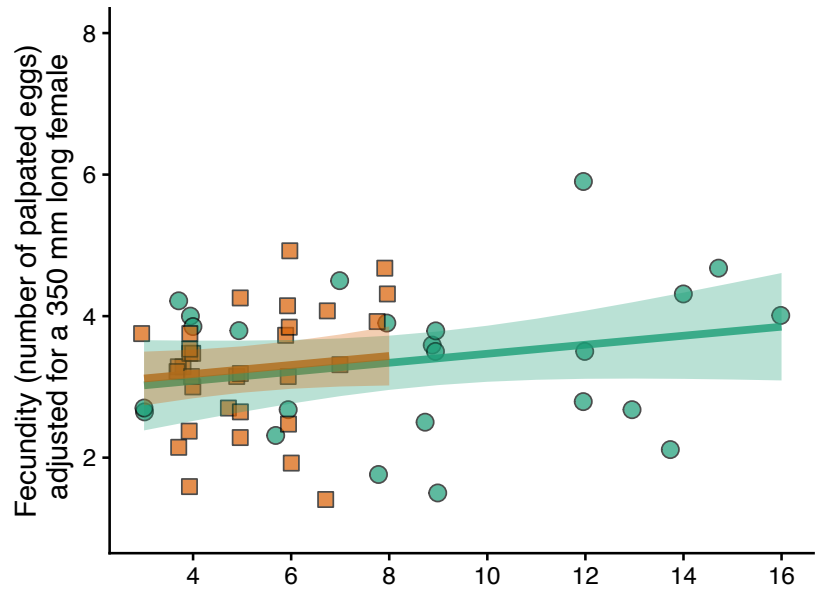

D

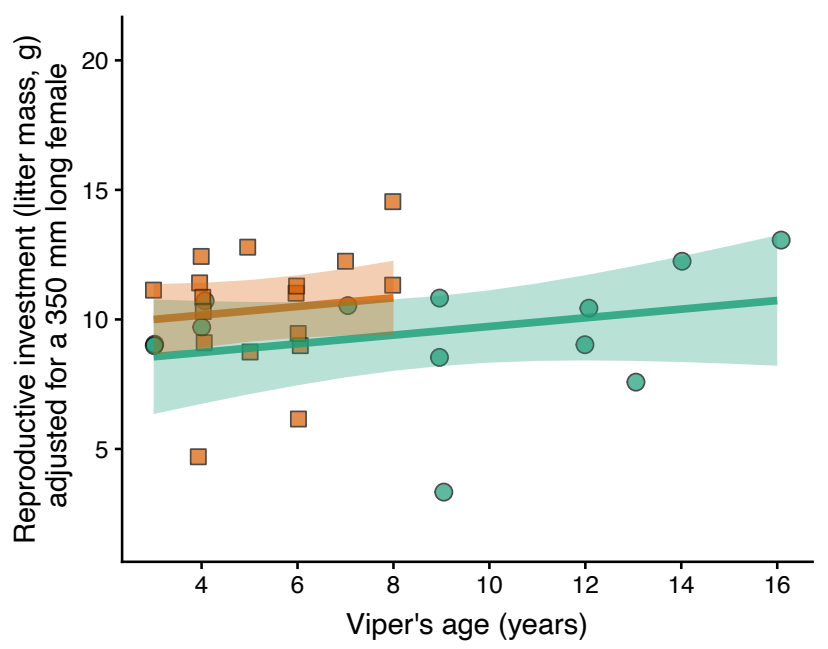

Figure 2: Effect of the female body length and age on their fecundity $(A, B)$ and reproductive investment (C, $D$ ). The panels $A$ and $C$ represent the positive (and habitat independent) relationships between female size and reproductive output. The panels $B$ and $D$ represent the negligible effects of age and habitat on these two traits after correcting for the positive effects of body length seen on the left panels. Lines (and 95\% Cl) are the predictions from the best models in Table S2 (models C1, C2, D1 and D2 respectively). 

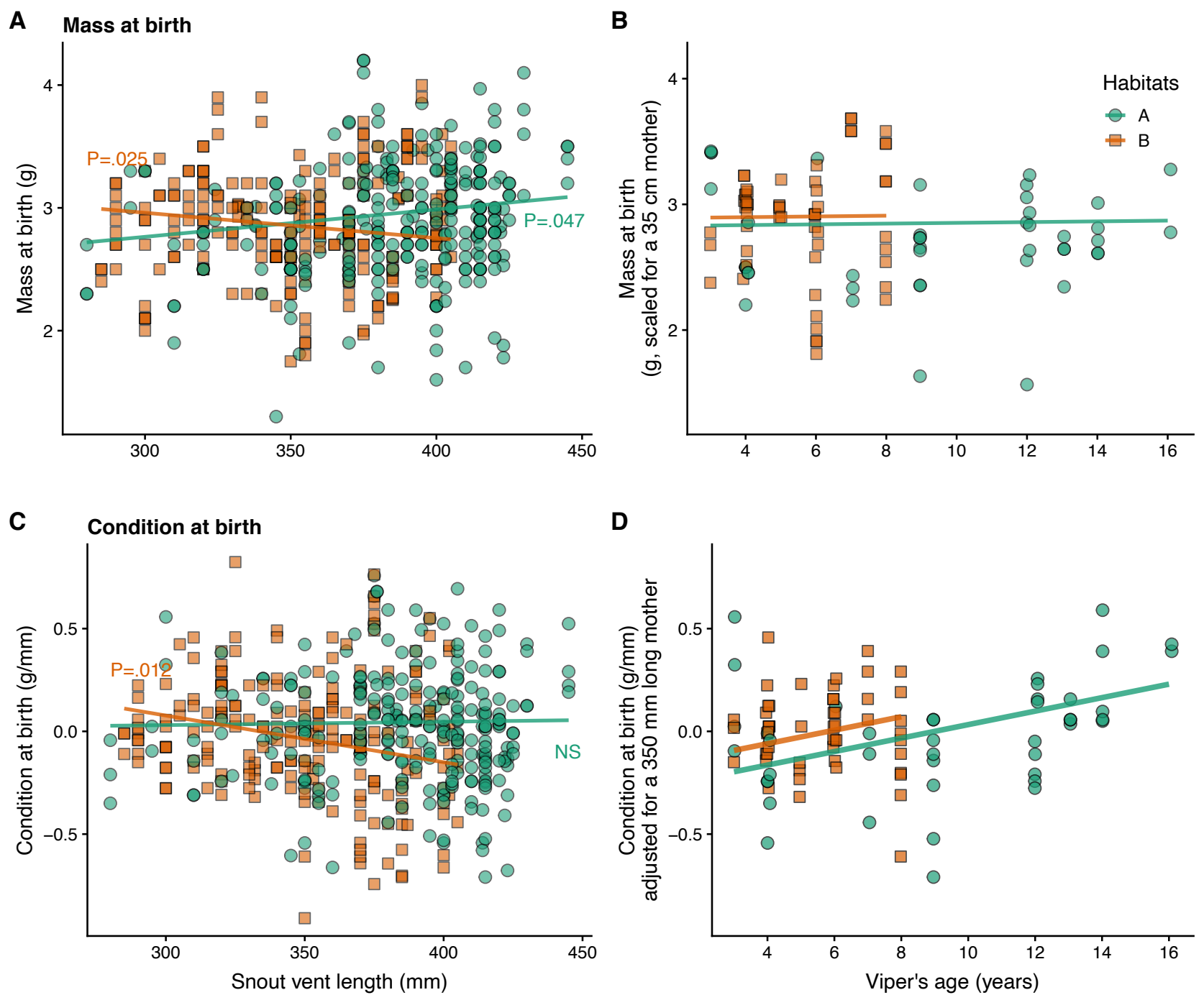

Figure 3: Effects of mother's age on the newborn traits. The panels $A$ and $C$ show the relation between offspring mass and condition at birth with their mother's length (snout-vent length). The panels B and D show the effects of mother's age on offspring mass and condition in the two habitats after controlling for the effect of mother's length seen in panels $\mathrm{A}$ and $\mathrm{C}$.

A

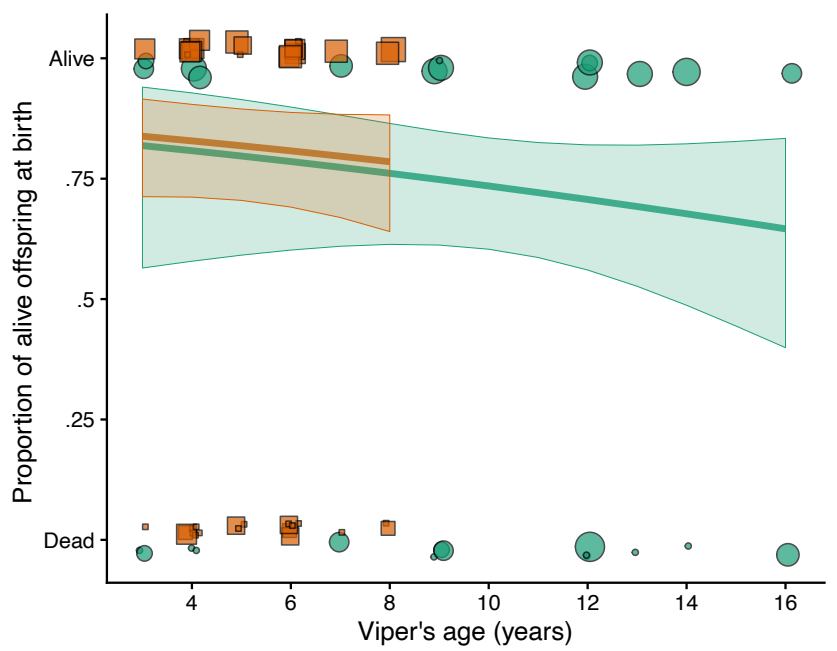

B

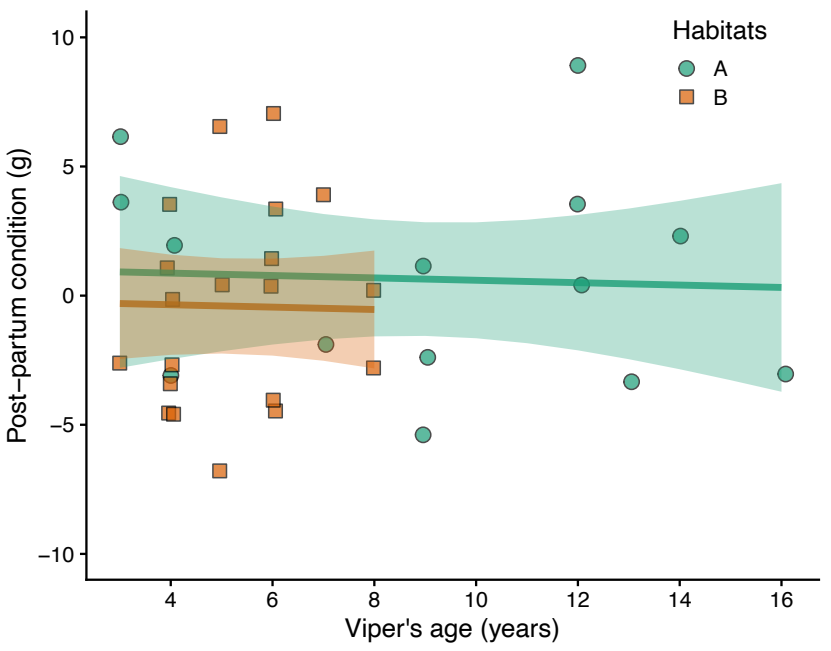

Figure 4: The litter success (proportion of alive offspring at birth) is similar between the two habitats and is not influenced by the mother's age (A). The post-partum body condition of the reproductive females does not vary between habitats and is not significantly influenced by female age (B). Predictions from the best models in Table S3 (models $\mathrm{G} 2$ and $\mathrm{H} 1$ ) have been plotted respectively on panels $\mathrm{A}$ and $\mathrm{B}$.

The pace and shape analysis of reproduction showed that the mean generation time (estimated as the average "mother-daughter distance") averaged 5 years in habitat B and 8 years in A (Supporting Information 3). As far as we know, this is the first estimation of generation time of a snake in the wild and it 
suggests that the pace of reproduction was faster in habitat $B$. In both habitats, we found that mean reproduction increased as vipers become older (Figure $\mathrm{S} 8 \mathrm{~B})$ and that the two standardised cumulative reproduction curves lied below the nil-senescence benchmark straight line (Figure S8F). This shape analysis (Supporting information 6) implies that negative senescence for reproduction is observed in this species. Qualitatively, this positive effect of age on reproduction was slightly stronger in habitat $B$ than in habitat $A$ (Figure S8F).

\section{Discussion}

The oldest individual observed in our study was a 16 years old female in habitat $A$. This maximum observed lifespan is pretty close to the observed maximum lifespan of 18 years in the garter snake (Sparkman et al., 2007) or to the reported maximum age of 15 and 18 years in two populations of asp vipers (Saint Girons, 1957). It has long been thought that such long-lived snakes can escape senescence: for example, in a seminal paper on the asp viper written more than seventy years ago (Saint Girons, 1957), the famous French herpetologist Hubert Saint Girons wrote "Nous pensons que la sénilité ne doit jouer qu'un rôle infime dans la structure des populations de serpents, la longévité potentielle étant très supérieure à la longévité réelle" (We believe senility should play only a small role in the structure of snake populations, the potential longevity being much greater than the actual longevity). This intuition proved to be quite visionary, although it rested on observations of longevity records and not on a quantification of age-dependent mortality or reproduction trajectories as we do nowadays. Yet, agetrajectories of adult mortality and reproduction of vipers are usually difficult to quantify accurately in the wild and empirical evidence has been lacking so far because the kinds of long-term longitudinal studies of marked individuals needed to measure the effect of age on mortality and reproduction are uncommon in this taxonomic group (Nussey, Coulson, FestaBianchet, \& Gaillard, 2008). To our knowledge, the western terrestrial garter snake is the only other snake species whose reproductive senescence has been studied in detail in the wild (Sparkman et al., 2007), whereas variation in mean longevity or mean adult survival (pace of mortality) has been quantified in a wide range of snake species (Stark et al., 2018). However, the life expectancy can be reduced because of an earlier onset of senescence, an increased rate of senescence or of an elevated baseline mortality, and these parameters can vary independently between and within species (Baudisch, 2011; Mallard et al., 2015). Thus, understanding how senescence has evolved in the wild in snakes requires a precise description of the age-trajectories of their life history traits and a separation of pace and shape of ageing. As far as we know, ours is the first study that provides such a detailed estimation of the mortality age-trajectories in a wild population of snakes.

\section{(a) Prediction 1: sex difference in longevity}

In line with our prediction 1, we found that the pace of mortality varied, albeit weakly, between sexes. Male meadow vipers suffered on average from higher adult mortality rates and thus had a shorter adult life expectancy than females in both habitats (Females $\sim 5.5$ years, Males $\sim 4$ years). This sexual difference in longevity is a classical pattern previously documented in other snakes (Bonnet, Naulleau, \& Shine, 1999), but is also more broadly observed in other squamate reptiles (Eckhardt, Kappeler, \& Kraus, 2017) or even other tetrapods (Austad \& Fischer, 2016; Colchero et al., 2016; Lemaître et al., 2020). In vipers, proximate explanations for this sex difference in adult life expectancy could be a malebiased adult mortality due to the earlier winter emergence of males, their higher locomotor activity especially during the mating season (spring) when they actively search for females, and a higher basal metabolism of males (Rollings et al., 2017). For example, the increased activity of male meadow vipers in unfamiliar and potentially riskier environments during the mating season might increase predation risks and mortality from a range of avian predators (Baron, 1997).

\section{(b) Prediction 2: negligible senescence}

We found no sign of decline of the female reproductive performances at advanced ages: old females maintained a high fecundity, a high reproductive investment, a high litter success and a high quality of their offspring (body size or and condition of neonates at birth) even at old ages. In female terrestrial garter snakes, a positive effect of age on fecundity and offspring size was found, whereas there was a slight negative senescence on relative clutch mass (Sparkman et al., 2007). However, the conclusions from Sparkman et al. (2007) for fecundity and offspring size must be interpreted with caution since the effect of age was largely confounded with size. Here, we found no effect of age on similar measures of female reproductive performances in the meadow viper when we quantified the ageing patterns independently from allometric effects of mother's body size and even a slight positive effect of maternal age on offspring body condition. In accordance with life history models (and with prediction 2 ), this indicates that negligible reproductive senescence is correlated with indeterminate growth. This condition satisfies a prerequisite condition for the theory for escaping actuarial senescence, which assumes a linkage between these traits (Vaupel et al., 2004).

\section{(c) Prediction 3: micro-geographic variation in the pace and shape of mortality}

Senescence patterns for mortality shifted from negligible in habitat $A$ to one characterised by a sharp mortality increase with advancing age in habitat $B$. These mortality trajectories are to our knowledge the first quantification of actuarial senescence for a 
snake species in the wild. In addition, our data provide a striking and unique empirical demonstration that the shape of the mortality trajectory in the wild can vary dramatically, even at a very small spatial scale thus confirming our prediction 3. In theory, the observed micro-geographic differences in the age structure and generation time aforementioned, if they have remained sufficiently stable, should change selective pressures on senescence (Wensink et al., 2017) and this could induce the long-term, genetic evolution of different patterns of actuarial senescence between the two sub-populations. However, it seems unlikely that the observed micro-geographic variation in actuarial senescence results only from genetic divergence of the two subpopulations given that the asphalt road that separates the two habitats is relatively recent ( $<60$ years old). In addition, we have gathered several observations of vipers crushed on the road showing that movement between the two habitats is rare, but not impossible, and that some, albeit low, gene flow may contribute to counter a potential genetic divergence between the two sub-populations (pers. obs.). Instead, we suggest that the micro-geographic shift in senescence patterns is most likely due to flexible changes in the shape of the mortality trajectories, which can be modified by ecological factors even at a very small spatial scale. Contrary to the striking differences seen for mortality trajectories, and despite differences in growth and body size between habitats (Baron et al., 2010b), reproductive performance traits, including litter size, litter mass and offspring traits, were indeed remarkably similar between the two habitats. This stability of reproductive traits between habitats, and during the whole lifespan, confirms that reproductive effort is strongly canalised in this species (Baron et al., 2013). The fact that differences in actuarial senescence patterns between the two habitats have occurred independently from reproductive senescence patterns further indicates that female vipers "prioritised" reproduction over survival as they aged.

In habitat $A$, characterised by a colder but wetter microclimate and by less human disturbance, our results offer also a compelling empirical evidence for negligible senescence even at oldest ages in a wild population of snakes in line with our prediction 2. This result stands in accordance with the theoretical expectation that negligible senescence can evolve in species with indeterminate growth for which reproductive output increases with body size (Vaupel et al., 2004; Baudisch, 2008). Indeed, there was a positive relation between fecundity (or reproductive investment) and body size for female meadow vipers in both habitats, and a positive relationship between the reproductive success of males and their size has been found in other viper species (Madsen, Shine, Loman, \& Håkansson, 1993). Thus, the non-senescent life history in habitat A may be a by-product of non-decreasing fecundity selection in females and selection for mating success in males as vipers get older (Vaupel et al., 2004; Baudisch, 2008). However, in habitat $B$, characterised by a warmer but drier microclimate (Figure S2) and by more human disturbance, females and males displayed increasing mortality as they aged, which stands against our

\section{prediction 2.}

The causal mechanism responsible for this potentially plastic shift in the mortality trajectories remains to be determined but such a modification is expected from the disposable soma theory when actuarial senescence is a consequence of a gap between the resources allocated to maintenance and the amount of resource required to prevent senescence (Wensink, van Heemst, Rozing, \& Westendorp, 2012). Within this framework, senescence in the meadow viper could be the consequence of stronger environmental constraints on energy acquisition associated with an inflexible reproductive strategy in the less optimal habitat $B$. We can hypothesise that self-maintenance was imperfect in habitat $B$ because reproduction is more costly in the sub-optimal habitat, the risks of thermal stress and hydric stress are stronger, and/or human disturbance causes increased physiological stress in vipers. First, maintaining a high reproductive performance throughout life in the less optimal habitat $B$ may entail some survival costs because of a trade-off between reproductive effort and selfmaintenance. Indeed, in habitat B, vipers grew more slowly, had lower post-parturition body condition and tended to breed less often (Baron et al., 2013; Baron et al., 2010a), but females maintained a high reproductive effort. The comparison of the shape of standardised cumulative reproduction even showed that the negative senescence of reproduction appeared stronger in habitat B. Second, due to differences in slope orientation, habitat $A$ was colder on average than habitat B. Low environmental temperatures have been shown to increase life expectancy across species in reptiles, probably because it reduces the metabolic rates and activity periods in these ectothermic animals (Stark et al., 2018). Water is another essential resource required for reproduction, and especially for embryonic development in vipers (Lourdais et al., 2017). In habitat B, microclimate was on average drier especially during the hottest periods of the day, which may have decreased the availability of free water as moist and increased cutaneous evaporative water loss. Water restriction can be critical especially during the long gestation period of vipers, which is associated with significant embryonic water uptake (Dupoué, Stahlschmidt, Michaud, \& Lourdais, 2015; Lourdais et al., 2017). Although reproductive performances of vipers may be resistant to changes in water availability during gestation in the environment (Dupoué et al., 2015), water deprivation during gestation increases maternal corticosterone levels and may thus represent an acute physiological stress (Dupoué et al., 2016). In addition, gestation is associated with an increased oxidative stress in vipers and gravid females exposed to water deprivation during gestation up-regulate antioxidant defences, most probably to shield their offspring from additional oxidative stress (Stier et al., 2017). The acute physiological stress and upregulation of antioxidant defences may represent a cost of reproduction to increasing mortality at old age. Third, an alternative explanation that we cannot rule out is that human-induced disturbances are higher in habitat $B$ during the active season leading to chronic stress for vipers. While habitat $A$ is relatively spared from heavy human disturbances during 
spring and summer seasons, habitat B attracts human visitors (pers. obs.). Recurrent presence of humans may generate disturbance stress leading on the long-term to a change in the mortality trajectories of vipers (French et al., 2017). Coupling our life-history data with ecophysiological measures may be necessary to improve our understanding of the proximal factors that causally explain flexibility in the shape of the mortality trajectories.

\section{Conclusions}

We have shown that, as expected, males have a shorter adult life expectancy than females and that, as hypothesised, negligible senescence can occur in species with an indeterminate growth. Yet, our results question the idea that negligible senescence is an universal feature of indeterminately growing species such as snakes. We anticipate that shifts from negligible to positive senescence in sub-optimal habitats may be common and argue for the case of considering more often low-quality habitats in future senescence research, such as population sinks, marginal populations, or poor quality cohorts. The micro-geographic variability of senescence patterns also highlights the need to revisit evolutionary models of ageing for slow and long-lived reptilian species to take into account not only the genetic components that determine the shape of the age-trajectories but also the plasticity of these trajectories and their sensibility to environmental factors. In ectothermic species, which are especially sensitive for environ- mental and climatic conditions, species-specific data reported in the literature should be interpreted with caution and future comparative analyses should take into account the potential for plastic changes in senescence.

\section{ACKNOWLEDGMENTS}

We are grateful to DIREN PACA and MEEDDAT for providing access to field sites and capture permits during our fieldwork and to the many workers who helped to collect data in the field. We thank Fernando Colchero for his help and advice for running the Bayesian survival models. We also deeply thank the two anonymous reviewers for their helpful advice.

\section{Authors' CONTRIBUtions}

JPB initiated the longitudinal study in 1979 and did the field work until its end in 2016. TT \& JFLG helped in the field work since 1999. JPB, TT \& JFLG conceived together the idea of the manuscript. TT analysed the data, produced the figures and wrote the first draft of the manuscript, and all authors contributed substantially to revisions.

\section{DATA ACCESSIBILITY}

Data is available on zenodo: 10.5281/zenodo.3900150 (Tully, Le Galliard, \& Baron, 2020). 


\section{SUPPORTING INFORMATION}

\section{Supporting Information 1 - Habitat description}

The study area includes open meadows of short grass with patches of juniper trees and rock outcrops that provide shelters and basking sites. The two habitats are separated by a $10 \mathrm{~m}$ large asphalt road (Figure S1) built in the sixties, which strongly limits vipers' movements. Habitat $A$ is relatively well isolated because it is limited by the road on its north side and surrounded by areas unfavourable to vipers. Habitat $B$ is less isolated, especially on its West side where it is connected to an extended meadow favourable to vipers. It is otherwise limited by the road and by a pine beech-forest on its East and North sides (Baron, 1997).

Air temperature and relative humidity records in the two habitats showed that on average habitat $A$ is colder and wetter than B (Figure S2). During the active season (between April and September) the temperature in the shade in habitat $\mathrm{B}$ is on average $2.4^{\circ} \mathrm{C}$ higher during the day (between 9 am and $6 \mathrm{pm}$ ) and $0.9^{\circ} \mathrm{C}$ higher during the night $(|t|>34, P<0.01)$. The below ground temperature is also different on average, although the difference is less pronounced than above ground. During the inactive season (between October and March), the soil is on average $0.24^{\circ} \mathrm{C}$ warmer in habitat $B(|t|=9.2, P<0.01$, Figure $S 2 A)$. Habitat $B$ is also dryer than $A$ : during the active season, in the shade of a juniper, the air is on average $13.2 \% \mathrm{RH}$ dryer in habitat $\mathrm{B}$ during the day and $7.3 \% \mathrm{RH}$ dryer during the night $(|t|>52, \mathrm{P}<0.01$, Figure $\mathrm{S} 2 \mathrm{~B})$. The humidity range is also very different between the two habitats: whereas, in $A$, humidity almost never drops below $50 \%$, in $B$ the humidity can reach values lower than $30 \%$ every sunny day during the active season (Figure S2 B).
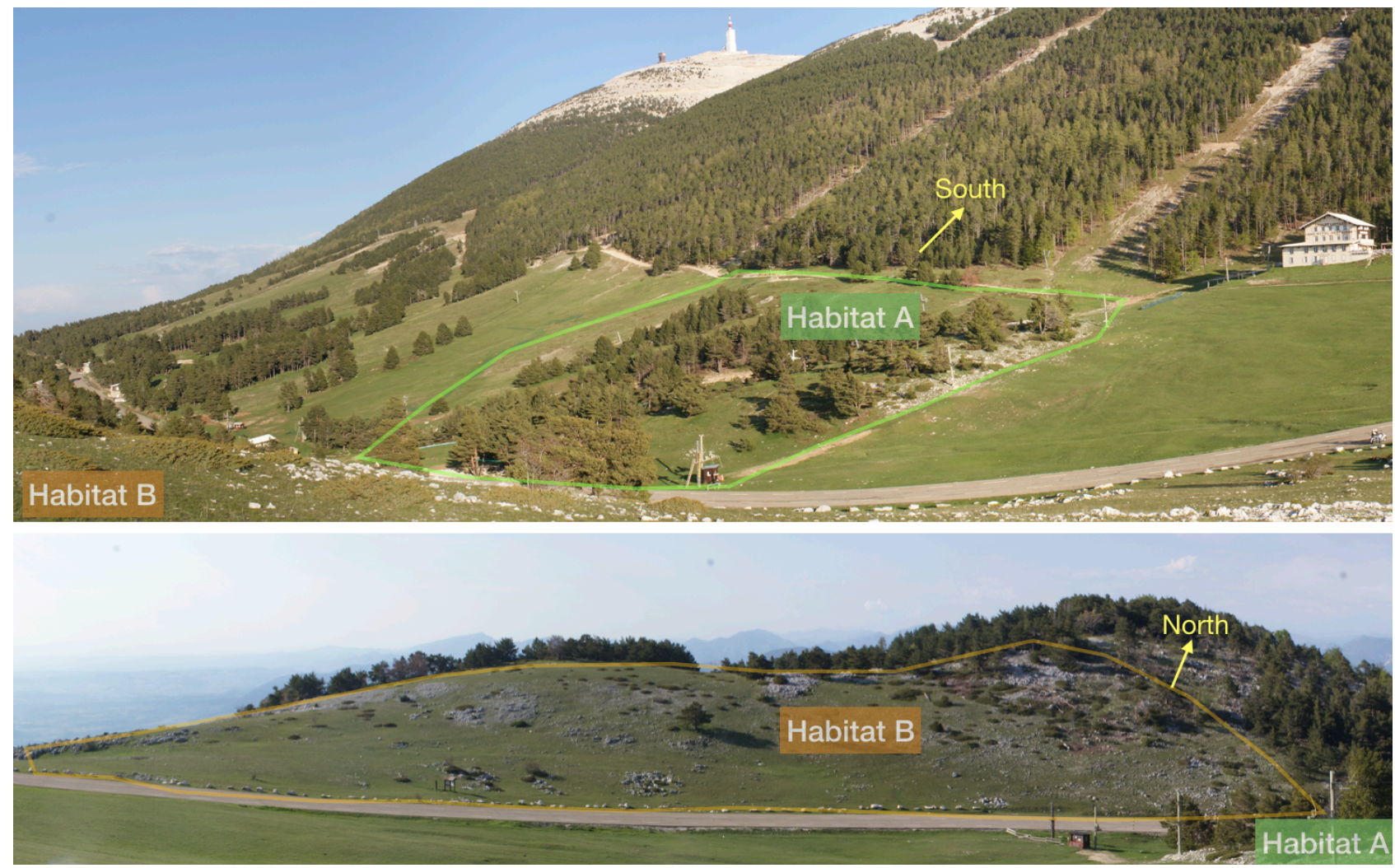

Figure S1: Pictures of the two habitats (T. Tully). 
A Mean temperature $(2008,2011-2017)$

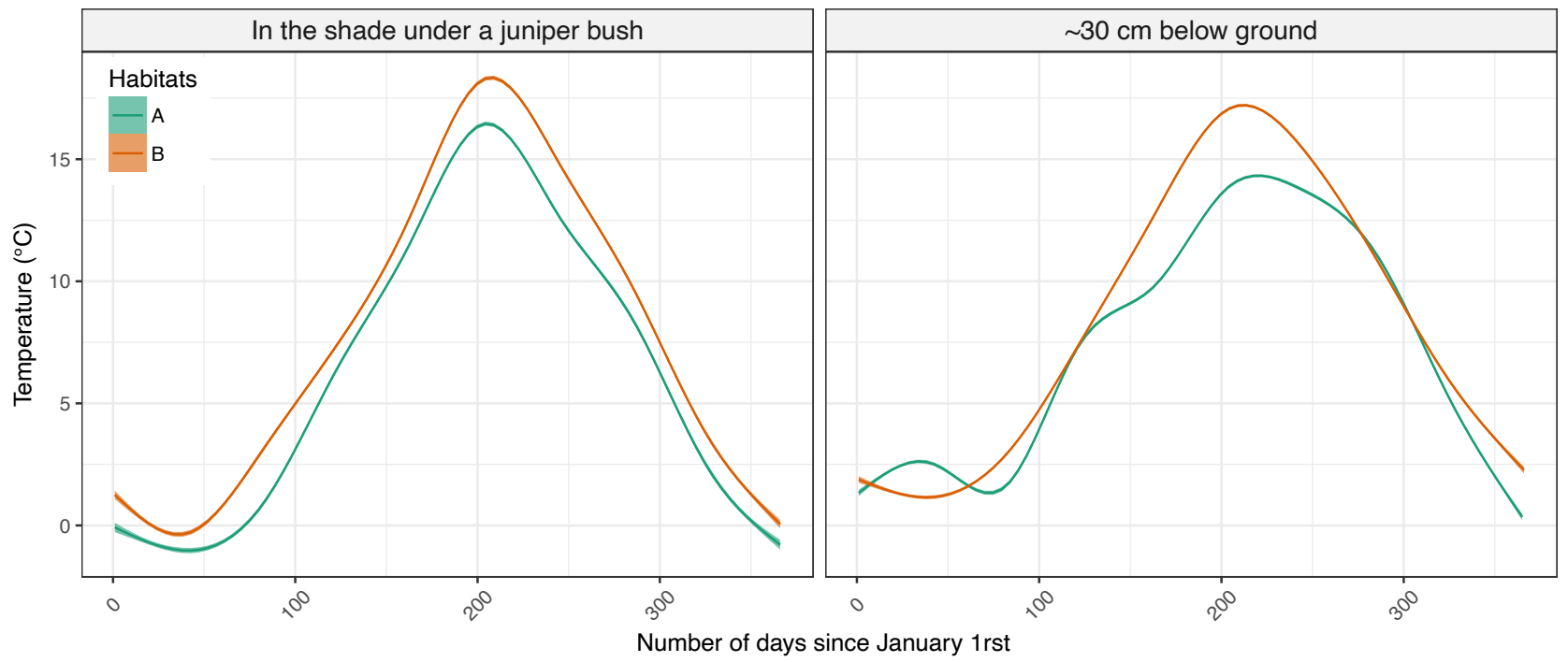

B Mean relative humidity under a juniper bush (2008)

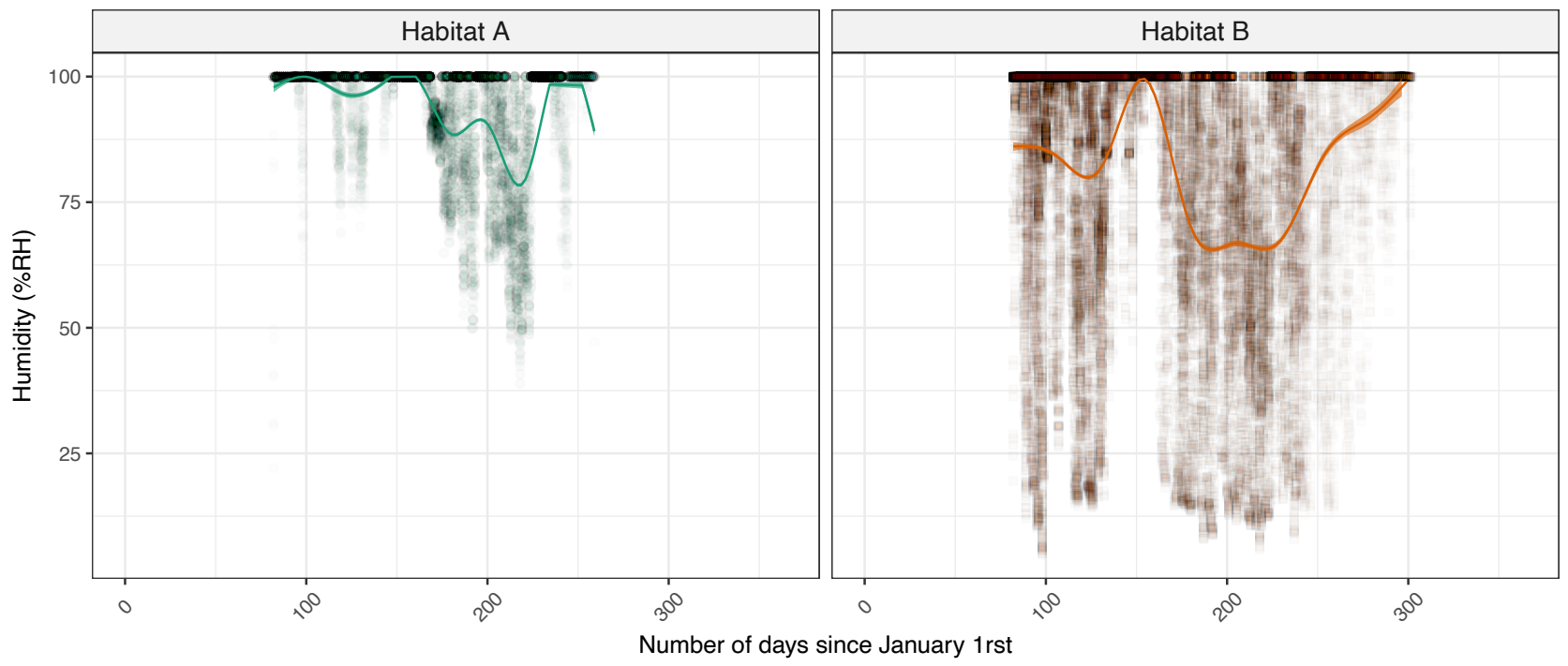

Figure S2: Microclimatic conditions recorded in the two habitats. (A) Temperatures were recorded in the shade of the junipers' bushes (left) where snakes can hide during the active season and $30 \mathrm{~cm}$ below ground (right) where the snakes hide during winter. Means are estimated using a gam function over the 203700 measurements collected during 8 years with temperature loggers. (B) Mean relative humidity (smoothed curves) and raw measurements (light dots) under juniper bushes in year 2008 (80 684 measurements). 


\section{Supporting Information 2 - Parturition dates}

The mean parturition date is similar between the two habitats and remained roughly stable since the beginning of the study despite inter-annual variation due to weather conditions (Figure S3).

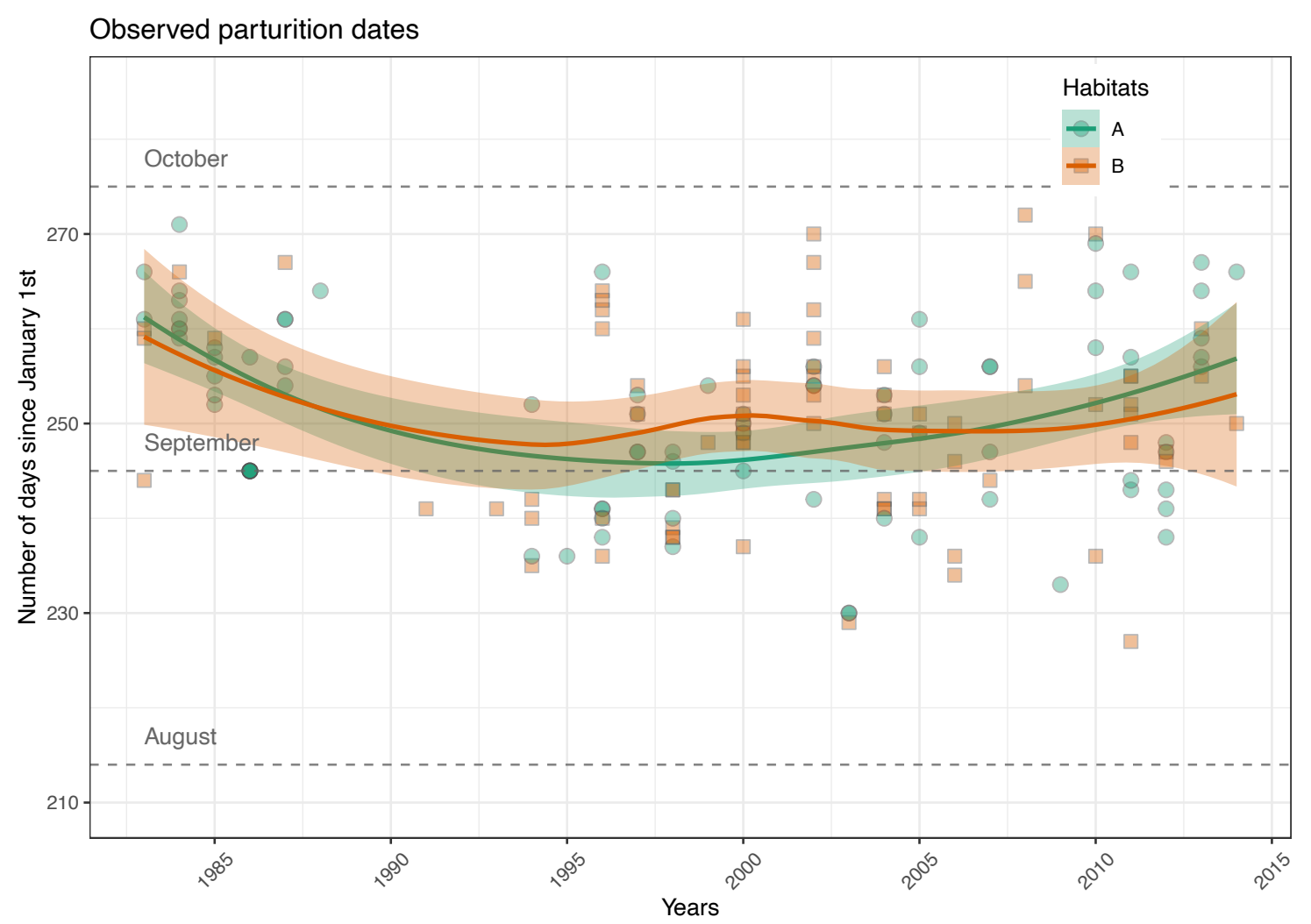

Figure S3: Parturition dates.

\section{Supporting Information 3 - The population age structure and estimated generation time}

The observed age structure does not represent the real age structure in the field since (1) some age classes are less observable than others (e.g. juveniles are difficult to observe during their first three years of life in the wild (Baron et al., 2010a) and (2) the age of old individuals can only be determined sometime after our field study started. A precise age could be attributed on average over the whole period to about one third of the individuals captured or observed in the field. This proportion was low at the beginning and regularly increased during the study and especially after 1994, when we started to mark the newborns at birth (Figure S4). Ten years after, from 2004 onwards, a little more than half of the individuals observed in the wild were of known age (Figure S4).

The mean observed age structure of the two sexes was calculated for the two habitats during the 2004-2016 period (Figure S5, data from 12 years after 2004 when about half of the captured individuals were of known age (Figure S4) and when the age of many old individuals could be determined). The observed age structure confirmed that the juveniles are very difficult to observe in the wild. It also shows that a significant part of the vipers can live for more than ten years in the wild and that the older individual observed in the population was a 16 years old female (born in 1998). This age structure also underlines the different longevities of the two sexes since the elderly individuals were mostly females (Figure S5). Finally, the age structure differs between the two habitats: in habitat $A$, the age structure was relatively uniform for the two sexes in contrast with habitat $B$ where the number of captured individuals declined regularly with age.

We used the 51 newborn females born from adult females of known age to measure the "generation time". Generation time was estimated here as the average "mother-daughter distance" which is the mean age difference between the reproductive females and their daughters (mean age of the reproductive females weighted by their number of female offspring). We found that the generation time ("mother-daughter distance") in habitat $A$ was 3 years longer than in habitat $B(A=8.3$ years $[7.1,9.495 \% \mathrm{Cl}], B=5.0$ years $[3.8$, $6.2], t=-3.99, P<0.001)$. 
Proportion of individuals of known age in the wild

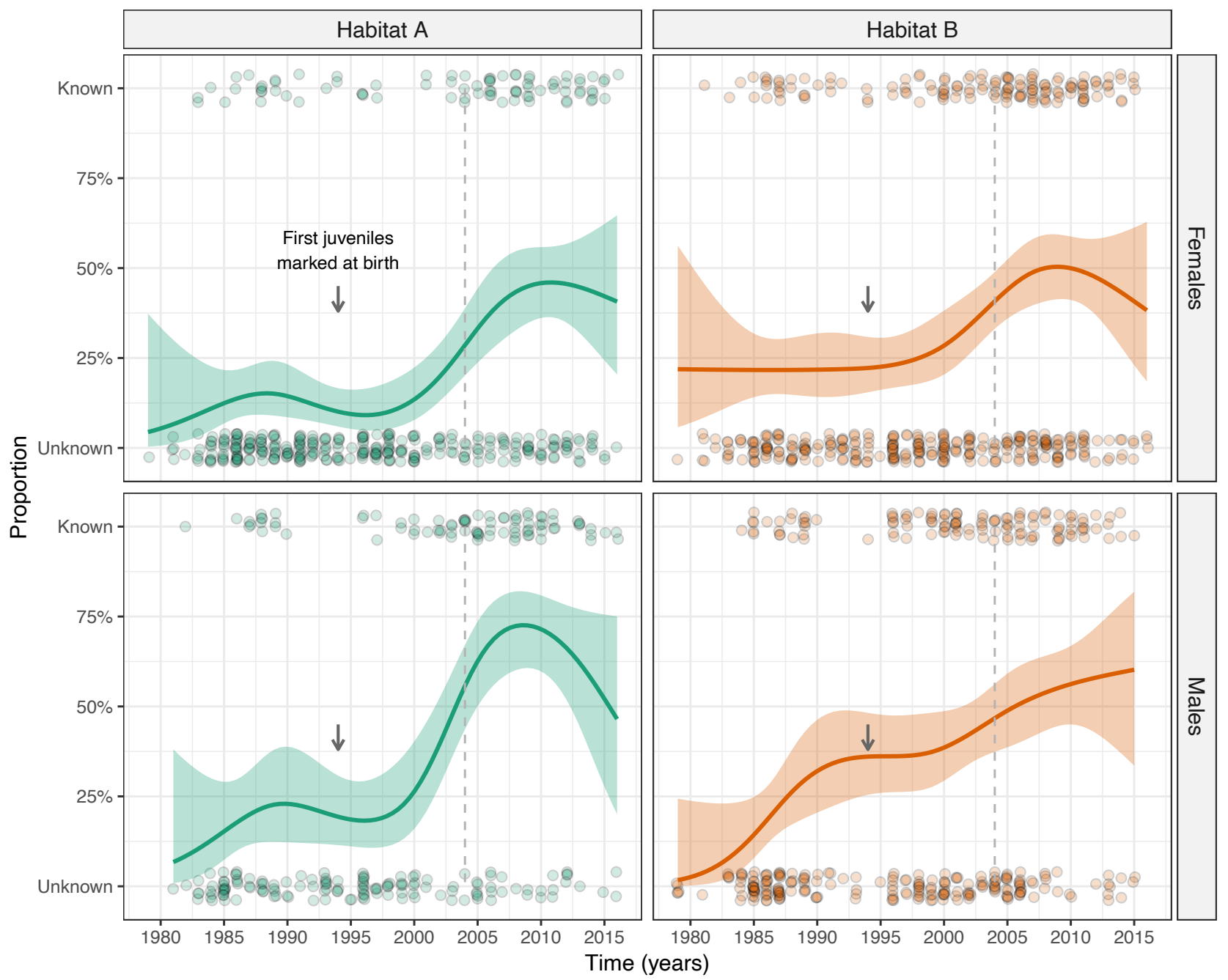

Figure S4: Panels plots of known age, unknown age and the proportion of known age vipers (binomial smooth spline) during the study in the two habitats and for males and females. We started to mark the newborns at birth in 1994 (arrow) and the proportion of individuals of known age started to increase a couple of years later to reach roughly $50 \%$ during the last decade of field work. We pooled all the observations made after 2004 (dotted line) to provide an estimation of the observed age structure in the population (Figure S5). 


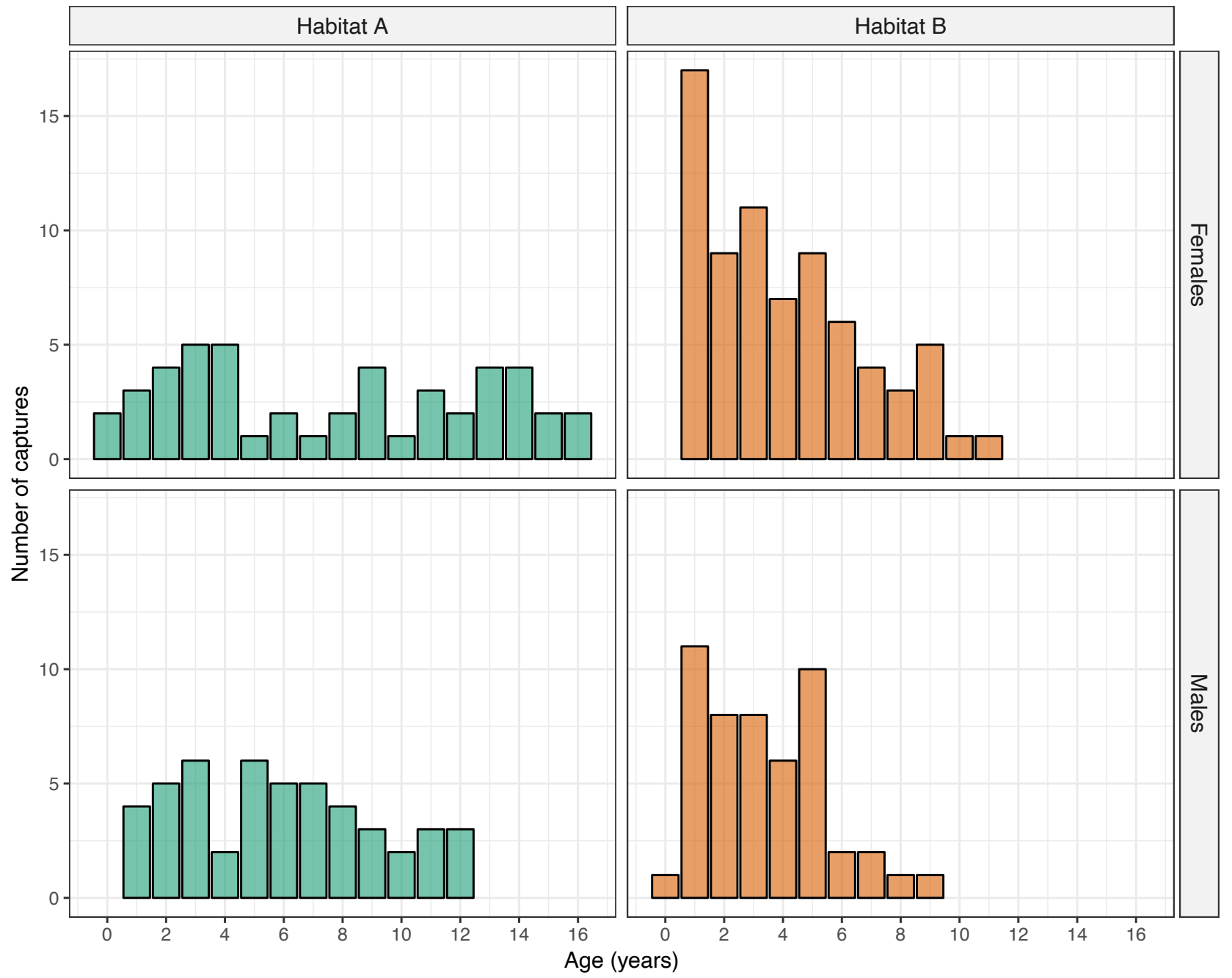

Figure S5: Observed age structure in the two habitats (A and B) and for the two sexes from 2004 to 2016.

\section{Supporting Information 4 - Details on the mortality models}

Table S1: Table with the different mortality models fitted, ordered by decreasing order of DIC for a given covariate structure. "Exponential, simple" refers to a function of constant mortality (which leads to an exponentially declining survivorship).

\begin{tabular}{|l|l|l|l|l|}
\hline Model $N^{\circ}$ & Mortality function & Shape & Categorical covariates & DIC \\
\hline 1 & Logistic & bathtub & None & 9369.8 \\
\hline 2 & Gompertz & bathtub & None & 9191.1 \\
\hline 3 & Weibull & bathtub & None & 8932.5 \\
\hline 4 & Exponential & simple & None & 8916.8 \\
\hline 5 & Gompertz & Makeham & None & 8914.8 \\
\hline 6 & Weibull & simple & None & 8879.2 \\
\hline 7 & Gompertz & simple & None & 8829.8 \\
\hline 8 & Logistic & simple & None & 8811.8 \\
\hline 9 & Logistic & Makeham & None & 8761.3 \\
\hline 10 & Weibull & Makeham & None & 8536.8 \\
\hline 11 & Exponential & simple & Sex (F,M) & 9161.3 \\
\hline 12 & Logistic & simple & Sex (F,M) & 8984.0 \\
\hline 13 & Logistic & bathtub & Sex (F,M) & 8897.1 \\
\hline 14 & Weibull & bathtub & Sex (F,M) & 8825.6 \\
\hline 15 & Gompertz & Makeham & Sex (F,M) & 8792.7 \\
\hline
\end{tabular}




\begin{tabular}{|c|c|c|c|c|}
\hline 16 & Weibull & Makeham & $\operatorname{Sex}(F, M)$ & 8607.3 \\
\hline 17 & Gompertz & bathtub & $\operatorname{Sex}(F, M)$ & 8537.0 \\
\hline 18 & Logistic & Makeham & $\operatorname{Sex}(F, M)$ & 8522.8 \\
\hline 19 & Gompertz & simple & $\operatorname{Sex}(F, M)$ & 8488.3 \\
\hline 20 & Weibull & simple & $\operatorname{Sex}(F, M)$ & 8278.5 \\
\hline 21 & Gompertz & Makeham & Sex*Habitat (FA, FB, MA, MB) & 8930.0 \\
\hline 22 & Gompertz & bathtub & Sex*Habitat (FA, FB, MA, MB) & 8925.2 \\
\hline 23 & Logistic & simple & Sex*Habitat (FA, FB, MA, MB) & 8786.1 \\
\hline 24 & Exponential & simple & Sex*Habitat (FA, FB, MA, MB) & 8705.4 \\
\hline 25 & Gompertz & simple & Sex*Habitat (FA, FB, MA, MB) & 8670.9 \\
\hline 26 & Weibull & simple & Sex*Habitat (FA, FB, MA, MB) & 8664.9 \\
\hline 27 & Logistic & Makeham & Sex*Habitat (FA, FB, MA, MB) & 8522.2 \\
\hline 28 & Logistic & bathtub & Sex*Habitat (FA, FB, MA, MB) & 8479.0 \\
\hline 29 & Weibull & Makeham & Sex*Habitat (FA, FB, MA, MB) & 8391.4 \\
\hline 30 & Weibull & bathtub & Sex*Habitat (FA, FB, MA, MB) & 8225.4 \\
\hline 31 & Logistic & simple & Sex+Habitat (FA, MA, B) & 10042.5 \\
\hline 32 & Logistic & bathtub & Sex+Habitat (FA, MA, B) & 8925.7 \\
\hline 33 & Exponential & simple & Sex+Habitat (FA, MA, B) & 8849.6 \\
\hline 34 & Gompertz & Makeham & Sex+Habitat (FA, MA, B) & 8828.3 \\
\hline 35 & Weibull & bathtub & Sex+Habitat (FA, MA, B) & 8818.3 \\
\hline 36 & Gompertz & bathtub & Sex+Habitat (FA, MA, B) & 8710.0 \\
\hline 37 & Logistic & Makeham & Sex+Habitat (FA, MA, B) & 8647.0 \\
\hline 38 & Weibull & Makeham & Sex+Habitat (FA, MA, B) & 8494.7 \\
\hline 39 & Weibull & simple & Sex+Habitat (FA, MA, B) & 8490.1 \\
\hline 40 & Gompertz & simple & Sex+Habitat (FA, MA, B) & 8428.9 \\
\hline 41 & Logistic & bathtub & Habitat $(A, B)$ & 9215.3 \\
\hline 42 & Gompertz & Makeham & Habitat $(A, B)$ & 8831.7 \\
\hline 43 & Weibull & bathtub & Habitat $(A, B)$ & 8810.8 \\
\hline 44 & Weibull & simple & Habitat $(A, B)$ & 8784.8 \\
\hline 45 & Gompertz & bathtub & Habitat $(\mathrm{A}, \mathrm{B})$ & 8693.2 \\
\hline 46 & Exponential & simple & Habitat $(A, B)$ & 8539.0 \\
\hline 47 & Weibull & Makeham & Habitat $(A, B)$ & 8456.3 \\
\hline 48 & Logistic & Makeham & Habitat $(A, B)$ & 8430.9 \\
\hline 49 & Logistic & simple & Habitat $(A, B)$ & 8393.3 \\
\hline 50 & Gompertz & simple & Habitat $(A, B)$ & 8209.1 \\
\hline
\end{tabular}




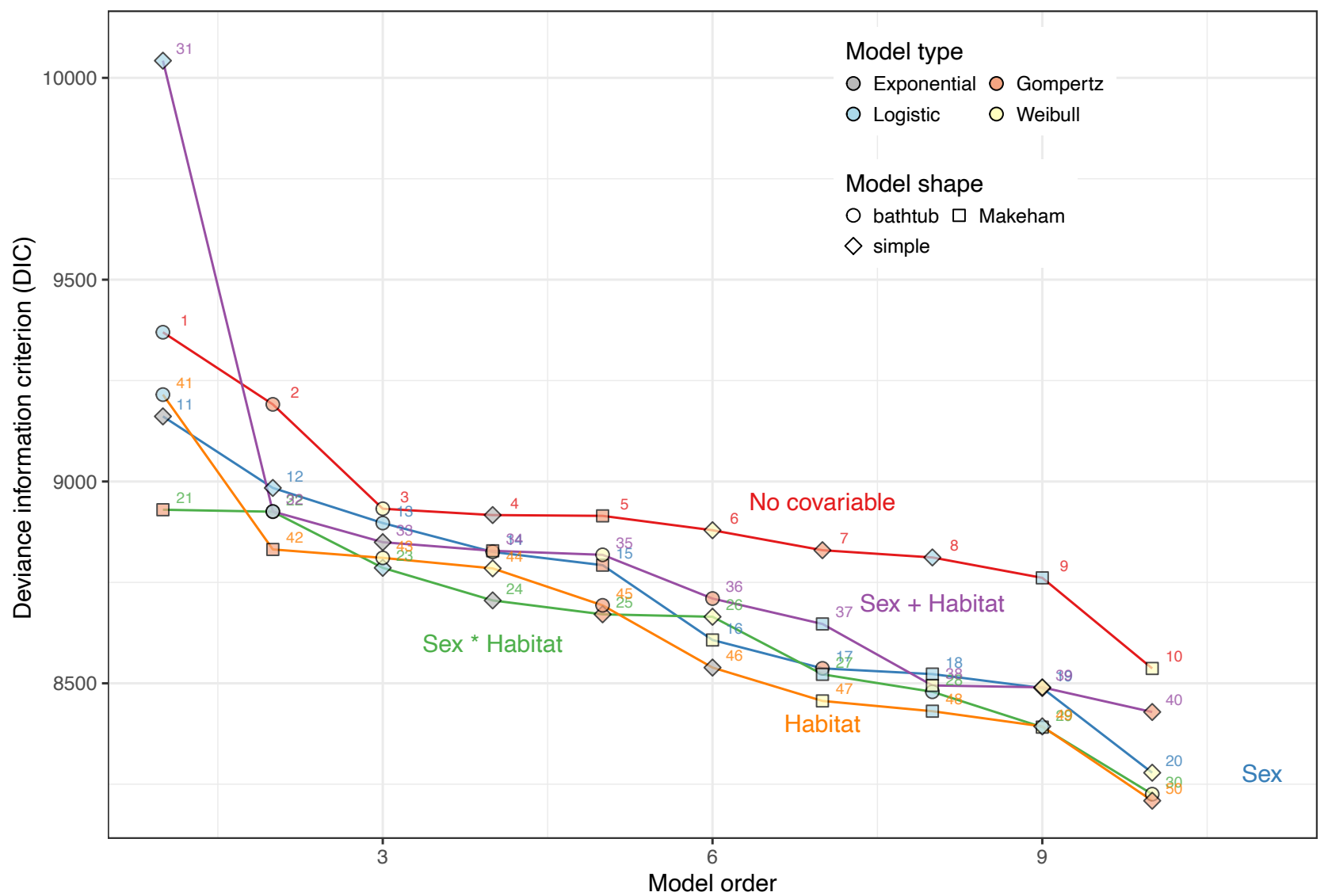

Figure S6: Model comparison. This plot represents the Deviance Information Criterion (DIC) for the 50 survival models. The models are organised in five groups depending on the covariables used (No covariable, Habitat only, Sex only, additive effect of Sex and Habitat and interaction between Sex and Habitat). For each of these five groups the different models (depending on model type and model shape) are sorted by decreasing DIC from left to right. The models with the best fits are those with the lowest DIC and are thus on the right side of the figure. Among those, the best models are models $\mathrm{N}^{\circ} 20,30$ and 50 (Table S1). The best models included a habitat effect and the top-ranking model was the model with habitat differences in mortality and a simple Gompertz shape, closely followed by the model with a two-way interaction between sex and habitat and a bathtub Weibull shape. These shapes allow the mortality rate to change with increasing age. 


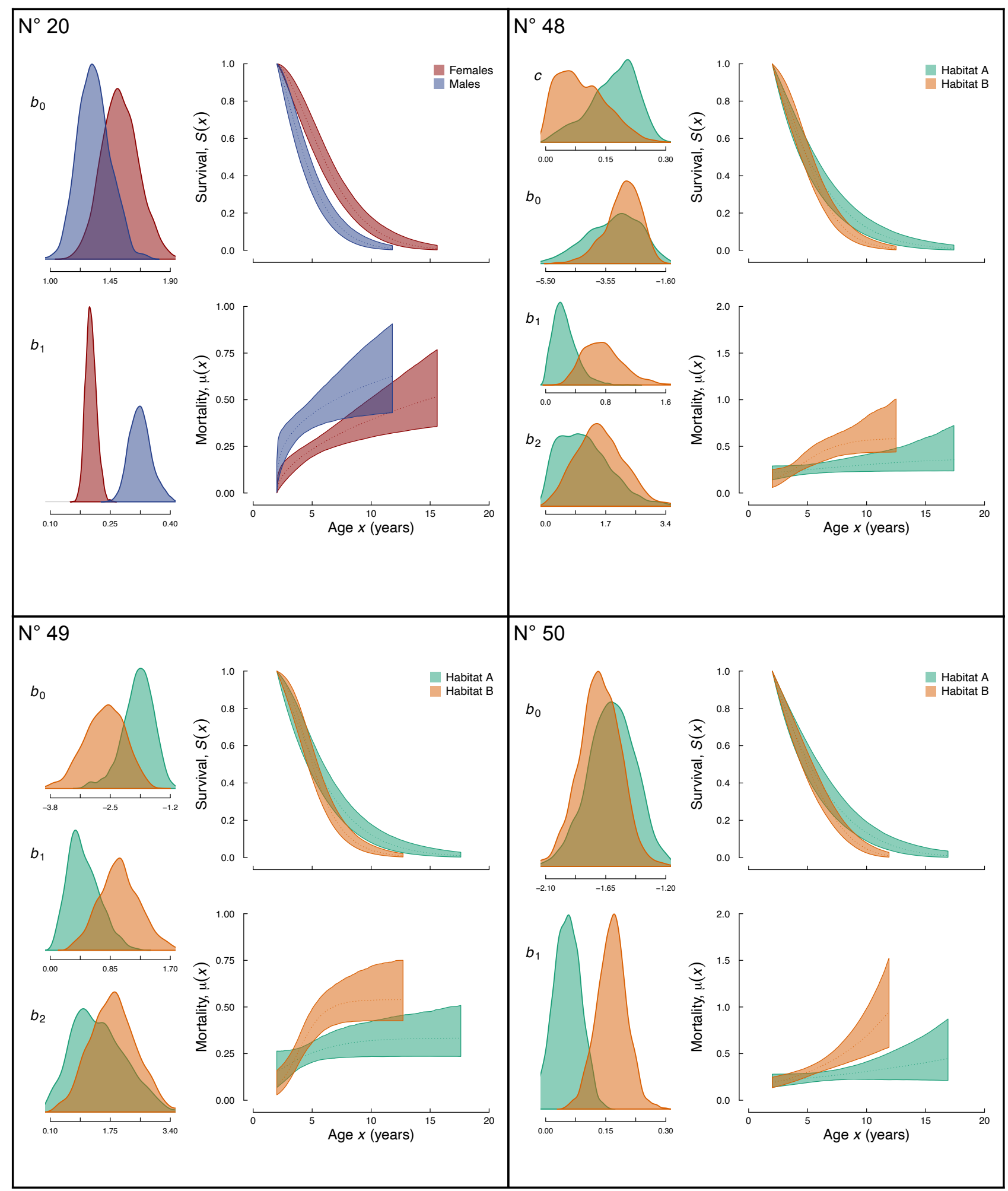




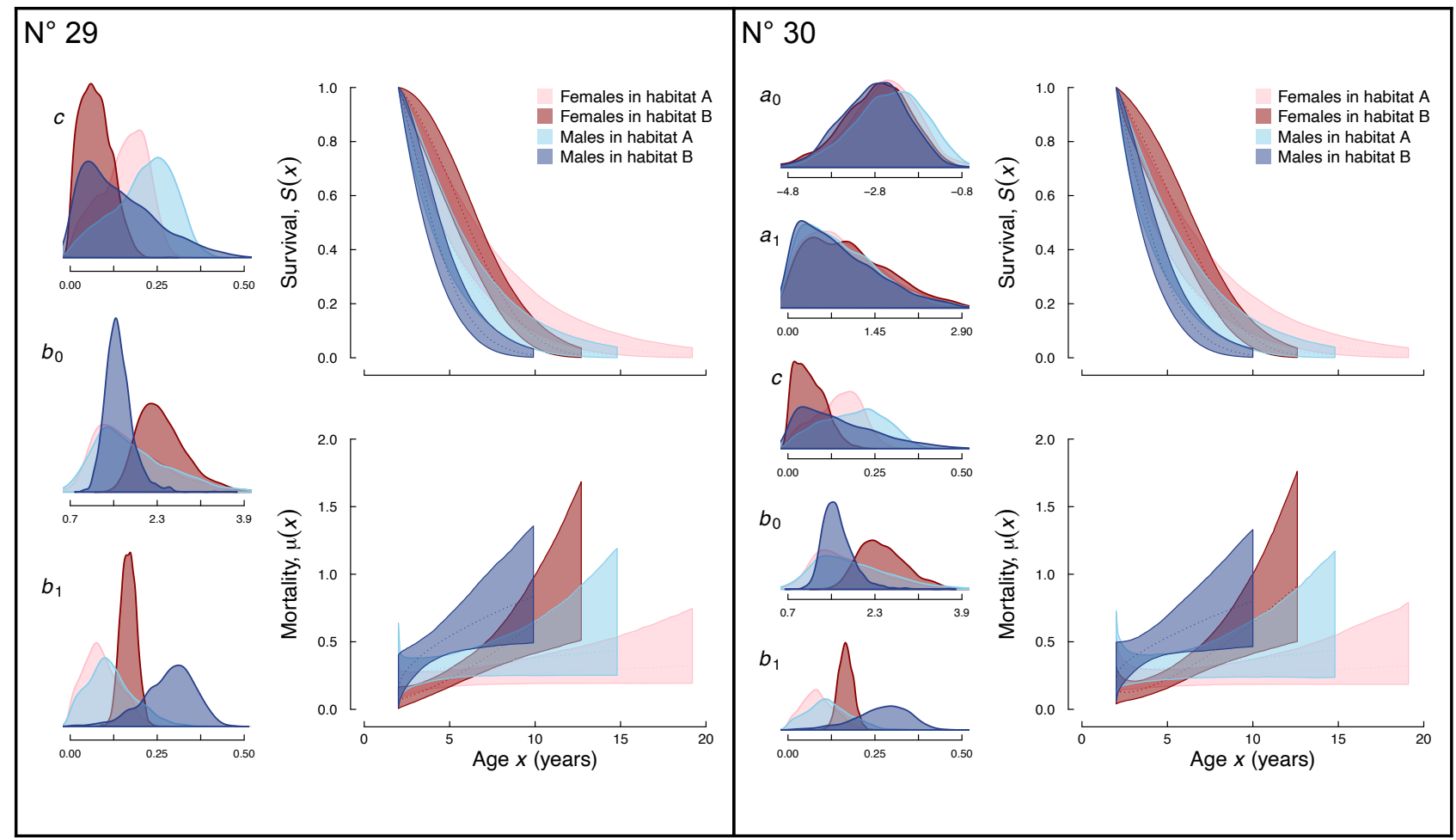

Figure S7: The six best models based on DIC. See Table S1 and Figure S6.

\section{Supporting Information 5 - Model tables}

Table S2: The effects of age and habitat on fecundity (C) and reproductive investment (D). Studied variables, their definition, and the statistical models and model results are explained. For each variable the sample mean is provided together with a $95 \%$ confidence interval estimate and the range of variation observed during the whole study. For both variables, we found a positive relationship with female length, and we then analysed the effect of age after controlling for the effect of female length (see method section for details). In the different models, we started with a full model with a two-way interaction between habitat and female covariates (size or age). We simplified these models when the interaction was non-significant (aligned on the right and italicised). When the interaction was nonsignificant, the tests for the simple effects come from the simplified model with no interaction. We provide type 3 ANOVA tests.

\begin{tabular}{|c|c|c|}
\hline \multicolumn{3}{|c|}{$\begin{array}{l}\text { (C) Fecundity (number of eggs counted by palpation be- } \\
\text { fore parturition) } \\
\text { Mean = } 3.8 \text { eggs; } 95 \% \mathrm{Cl}=[3.6-3.9] \text {; Range }=1-8 \\
\text { Positive Poisson linear models }(\mathrm{vg} / \mathrm{m}) \text {. }\end{array}$} \\
\hline $\begin{array}{l}\text { (C1) Fecundity and female's length } \\
\text { (SVL). } N=191 \text {. Figure } 2 A\end{array}$ & $\mid Z$ value $\mid$ & $\begin{array}{c}P \\
\text { valu } \\
e\end{array}$ \\
\hline Female's length & 5.16 & $\begin{array}{c}<0.0 \\
01\end{array}$ \\
\hline Habitat (A/B) & 0.391 & 0.69 \\
\hline SVL ${ }^{*}$ Habitat & 0.234 & 0.81 \\
\hline
\end{tabular}

\begin{tabular}{|l|c|c|}
\hline $\begin{array}{l}\text { (C2) Fecundity corrected for the length } \\
\text { (residuals of model A1) and age of fe- } \\
\text { male. Gaussian linear model. N= 56. } \\
\text { Figure 2B }\end{array}$ & $t$ value & $\begin{array}{c}P \\
(>|t|)\end{array}$ \\
\hline Female's age & 1.418 & 0.16 \\
\hline Habitat & 0.324 & 0.75 \\
\hline Female's age *Habitat & 1.11 & 0.27 \\
\hline
\end{tabular}

(D) Reproductive investment (clutch mass, including water and residual tissues from amnion and allantois, g) Mean $=10.79 \mathrm{~g} ; 95 \mathrm{Cl}=[10.21-11.37] ;$ Range $=1.60-$ $20.72 \mathrm{~g}$

Gaussian linear mixed model (Imer) with female's identity as random factor.

\begin{tabular}{|c|c|c|}
\hline $\begin{array}{l}\text { (D1) Litter mass and length of female } \\
\text { (SVL). } N=139 . \text { Figure } 2 \mathrm{C}\end{array}$ & $\begin{array}{l}\text { F value } \\
\text { (Df) }\end{array}$ & $\begin{array}{c}\mathrm{P} \\
\text { valu } \\
\mathrm{e}\end{array}$ \\
\hline Female's length & $\begin{array}{c}42.4(1 \\
44)\end{array}$ & $\begin{array}{c}<0.0 \\
01\end{array}$ \\
\hline Habitat (A/B) & $\begin{array}{l}0.0004 \\
(1,92)\end{array}$ & 0.98 \\
\hline SVL * Habitat & $\begin{array}{c}0.07(1 \\
43)\end{array}$ & 0.79 \\
\hline \multicolumn{3}{|c|}{$\begin{array}{l}\text { (D2) Litter mass corrected for length of female }(35 \mathrm{~cm}) \\
\text { and female's age. } N=30 . \text { Figure 2D }\end{array}$} \\
\hline Female's age & $\begin{array}{l}0.2536 \\
(1,10)\end{array}$ & $\begin{array}{c}0.62 \\
55\end{array}$ \\
\hline Habitat & $\begin{array}{l}1.9903 \\
(1,17)\end{array}$ & $\begin{array}{c}0.17 \\
63\end{array}$ \\
\hline Female's age * Habitat & $\begin{array}{c}0.5591 \\
(1,9)\end{array}$ & $\begin{array}{c}0.47 \\
37\end{array}$ \\
\hline
\end{tabular}


Table S3: Effects of maternal length, age and habitat on newborn mass $(E)$ and condition $(F)$ at birth. Please refer to method and to the details provided in the legend of Table S2. When the interaction between mother's age and habitat was significant, we also provide the results of the sub-models fitted for each habitat separately (models E, F).

(E) Newborn mass (measured just after parturition on 496 alive vipers from 138 reproductive events in the laboratory, g)

Mean $=2.9 \mathrm{~g} ; 95 \% \mathrm{Cl}=[2.8-3 \mathrm{~g}] ;$ Range $=1.3-4.2 \mathrm{~g}$ Gaussian linear mixed models (Imer) with mother's identity as random factor.

\begin{tabular}{|l|c|c|}
\hline $\begin{array}{l}\text { (E1) Newborn mass and mother's } \\
\text { length before parturition. } \mathrm{N}=496\end{array}$ & $\mathrm{~F}$ value (Df) & $\begin{array}{c}\mathrm{P} \\
\text { value }\end{array}$ \\
\hline $\begin{array}{l}\text { Mother's length (A, slope }= \\
0.006 \mathrm{~g} / \mathrm{mm})\end{array}$ & $\begin{array}{c}3.8749(1, \\
396)\end{array}$ & 0.049 \\
\hline Habitat (B>A, Contrast $=+1.48 \mathrm{~g})$ & $\begin{array}{c}5.3363(1, \\
95)\end{array}$ & 0.023 \\
\hline $\begin{array}{l}\text { Mother's length * Habitat (B<A, } \\
\text { contrast slope = -0.004) }\end{array}$ & $\begin{array}{c}5.9810(1, \\
397)\end{array}$ & 0.015 \\
\hline
\end{tabular}

(E2) Newborn mass and mother's length in habitat $A . N=$ 273

\begin{tabular}{|l|c|l|}
\hline Mother's length $(+0.0023 \mathrm{~g} / \mathrm{mm})$ & $\begin{array}{c}4.000(1, \\
224)\end{array}$ & 0.047 \\
\hline $\begin{array}{l}\text { (E3) Newborn mass and mother's } \\
\text { length in habitat B. N = 223 }\end{array}$ & & \\
\hline Mother's length $(-0.0030 \mathrm{~g} / \mathrm{mm})$ & $\begin{array}{c}5.11149(1, \\
173)\end{array}$ & 0.025 \\
\hline
\end{tabular}

(E4) Newborn mass corrected for mother's length (350 $\mathrm{mm}$ ) and mother's age. $\mathrm{N}=100$

\begin{tabular}{|l|c|c|}
\hline Mother's age & $\begin{array}{c}0.0372(1, \\
79)\end{array}$ & 0.847 \\
\hline Habitat & $\begin{array}{c}0.1406(1, \\
18)\end{array}$ & 0.712 \\
\hline Mother's age * Habitat & $\begin{array}{c}2.1072(1, \\
78)\end{array}$ & 0.151 \\
\hline
\end{tabular}

(F) Newborn condition (estimated as the residuals of a linear model of newborn mass against newborn SVL at birth, $(\mathrm{g} / \mathrm{mm}))$.

Gaussian linear mixed models (Imer) with mother's identity as random factor.

\begin{tabular}{|l|c|c|}
\hline $\begin{array}{l}\text { (F1) Newborn condition at birth } \\
\text { and mother's length. } \mathrm{N}=468\end{array}$ & $\mathrm{~F}$ value (Df) & $\begin{array}{c}\mathrm{P} \\
\text { value }\end{array}$ \\
\hline Mother's length & $\begin{array}{c}0.050(1, \\
372)\end{array}$ & 0.823 \\
\hline $\begin{array}{l}\text { Habitat (B>A, Contrast }=0.776 \mathrm{~g} / \\
\mathrm{mm})\end{array}$ & $3.530(1,88)$ & 0.063 \\
\hline $\begin{array}{l}\text { Mother's length * Habitat }(\mathrm{B}<\mathrm{A}, \\
\text { contrast slope }=-0.0024)\end{array}$ & $\begin{array}{c}4.631(1, \\
371)\end{array}$ & 0.032 \\
\hline
\end{tabular}

(F2) Newborn condition and mother's length in habitat A. $\mathrm{N}=258$

\begin{tabular}{|l|c|c|}
\hline Mother's length & $\begin{array}{c}0.052(1, \\
210)\end{array}$ & 0.819 \\
\hline
\end{tabular}

(F3) Newborn condition and mother's length in habitat $B$. $\mathrm{N}=210$

\begin{tabular}{|l|l|l|}
\hline Mother's length $(-0.0023(\mathrm{~g} / \mathrm{mm}) /$ & $6.462(1,163)$ & 0.012 \\
\hline
\end{tabular} $\mathrm{mm}$ )

(F4) Newborn condition at birth $(\mathrm{g} / \mathrm{mm})$ and mother's age. $\mathrm{N}=95$

\begin{tabular}{|c|c|c|}
\hline $\begin{array}{l}\text { Mother's age (overall positive } \\
\text { effect) }\end{array}$ & $14.46(1,74)$ & 0.0003 \\
\hline Habitat & $5.141(1,17)$ & 0.348 \\
\hline Mother's age * Habitat & $0.242(1,74)$ & 0.624 \\
\hline \multicolumn{3}{|c|}{$\begin{array}{l}\text { (F5) Newborn condition and mother's age for mothers } \\
\text { younger than } 10 \text { years old. }\end{array}$} \\
\hline $\begin{array}{l}\text { Mother's age (overall positive } \\
\text { effect) }\end{array}$ & $0.798(1,56)$ & 0.375 \\
\hline Habitat & $0.490(1,16)$ & 0.494 \\
\hline Mother's age * Habitat & $0.788(1,55)$ & 0.379 \\
\hline
\end{tabular}

(G) Litter success (or newborn viability or hatching success $=$ proportion of eggs from a litter that produced living newborns. The unsuccessful eggs were either unfertilised eggs or fertilised eggs that produced aborted or dead young vipers)

Mean litter success $=77.5 \% ; 95 \% \mathrm{Cl}=[69.5-84.3 \%]$

Generalised linear mixed model (glmer, binomial) with mother's identity as random factor.

\begin{tabular}{|c|c|c|}
\hline $\begin{array}{l}\text { (G1) Litter success and mother's } \\
\text { length. } N=156\end{array}$ & $\mid Z$ value $\mid$ & $\begin{array}{c}P \\
\text { value }\end{array}$ \\
\hline Mother's length before parturition & 0.964 & 0.3348 \\
\hline Habitat & 0.493 & 0.6222 \\
\hline Mother's length * Habitat & 1.061 & 0.2887 \\
\hline $\begin{array}{l}\text { (G2) Litter success and mother's } \\
\text { age. } N=34\end{array}$ & $\mid Z$ value $\mid$ & $\begin{array}{c}P \\
\text { value }\end{array}$ \\
\hline Mother's age & 0.929 & 0.3531 \\
\hline Habitat & 0.240 & 0.8103 \\
\hline Mother's age * Habitat & 0.858 & 0.3907 \\
\hline
\end{tabular}

(H) Female's post-partum condition (estimated as the residuals of a linear model of the female's mass right after parturition against body length, g)

Gaussian linear model $(\mathrm{Im})$.

\begin{tabular}{|c|c|c|}
\hline (H1) Condition. $\mathrm{N}=34$ & $\mid Z$ value $\mid$ & $\begin{array}{c}P \\
\text { value }\end{array}$ \\
\hline Female's age & 0.0369 & 0.8489 \\
\hline Habitat & 0.5533 & 0.4626 \\
\hline Female's age * Habitat & 1.0193 & 0.3208 \\
\hline
\end{tabular}




\section{Supporting Information 6 - Measuring the shape of reproduction}

To calculate the cumulative reproduction, we first modelled the relation between the age $x$ and fecundity of the reproductive females $F(x)$, with a quasipoisson generalised linear model (Table S4, Figure S8B). In parallel, we estimated the probability that a female produces a litter (reproductive state) as a function of its age $P(x)$ (Figure S8C) using age at maturation data and the transition probabilities between the reproductive and non-reproductive states in adults estimated in an earlier publication (Baron et al., 2013). This probability was estimated between $\alpha$, the age of first reproduction ( 3 years in the two habitats) and $\beta$, the last age of reproduction. $\beta$ was estimated in each habitat as the age when $99 \%$ of the individuals have died, using the survival curves from Figure 1A (dots on the right). The age-specific maternity function $m(x)$, which provides the average number of offspring to a mother of age $x$ (Figure S8D) is simply the product of the fecundity function $F(x)$ (Figure $\mathrm{S} 8 \mathrm{~B})$ with the probability of reproducing function $P(x)$ (Figure S8C): $m(x)=F(x)^{*} P(x)$. In Figure S8D, the horizontal dotted lines represent the maternity function when fertility is constant over the reproductive lifespan ( $\beta-\alpha)$ and can be used as a benchmark for the case of nil-senescence (Baudisch \& Stott, 2019). From the $m(x)$ function (Figure S8D), one can then compute the cumulative reproductive function $B(x)$ (Figure S8E), which gives the expected total number of offspring produced by a female of age $x$. A standardisation is then required to compare the shape of reproduction (fertility) of the females from the two habitats differing in the duration of their reproductive lifespans and of their maximum reproductive output. Age standardisation $x_{s}$ consists in dividing age since first reproduction ( $\alpha=3$ years) by the duration of the reproductive lifespan: $x_{s}=(x-\alpha) /(\beta-\alpha)$. Standardised cumulative reproduction $B_{s}(x)$ can be obtained by dividing $B(x)$ with the maximum reproduction achieved at the end of the reproductive lifespan i.e. when $x=\beta$ (Figure S8E). Finally, the standardised cumulative reproduction against standardised age, called here $\mathrm{B}_{s}\left(\mathrm{X}_{s}\right)$, can be used to compare the "shape of reproduction" in the two habitats and to assess if reproductive senescence is observed (Figure S8F). Negative reproductive senescence occurs when the standardised cumulative function $B_{s}$ lies above the nil-senescence benchmark case (dotted line) and positive reproductive senescence is highlighted when $\mathrm{B}_{s}$ lies underneath the constant equivalent.

Table S4: The effect of age and habitat on the fecundity of reproductive female.

\begin{tabular}{|c|c|c|}
\hline \multicolumn{3}{|c|}{$\begin{array}{l}\text { Fecundity (number of eggs counted by palpation before } \\
\text { parturition) } \\
\text { Quasi Poisson linear models }(\mathrm{g} / \mathrm{m}) \text {. }\end{array}$} \\
\hline $\begin{array}{l}\text { Fecundity and female's age. } \mathrm{N}=191 . \\
\text { Figure S8B }\end{array}$ & $\begin{array}{l}\mid \mathrm{t} \\
\text { value } \mid\end{array}$ & $P$ value \\
\hline Female's age & 3.17 & 0.002 \\
\hline Habitat $(\mathrm{A} / \mathrm{B})$ & 1.94 & 0.057 \\
\hline Age * Habitat & 2.03 & 0.047 \\
\hline
\end{tabular}


A

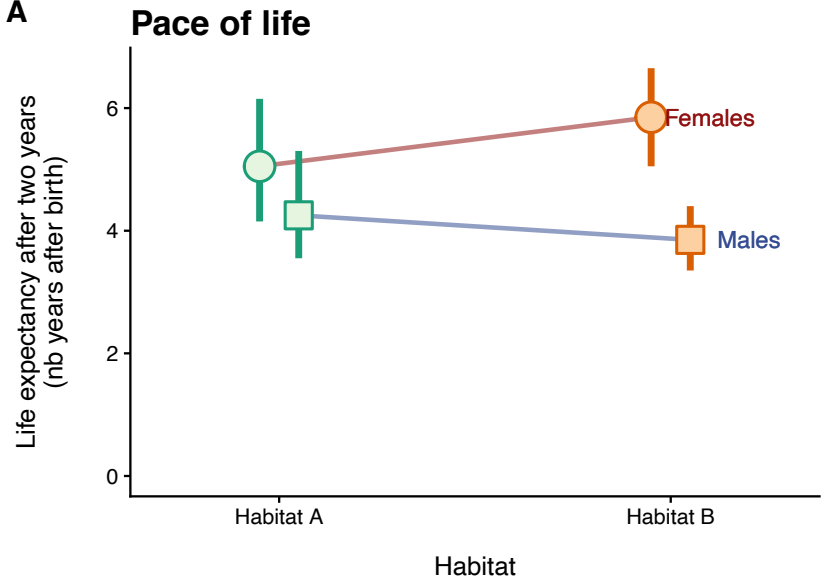

C Proportion of breeding females

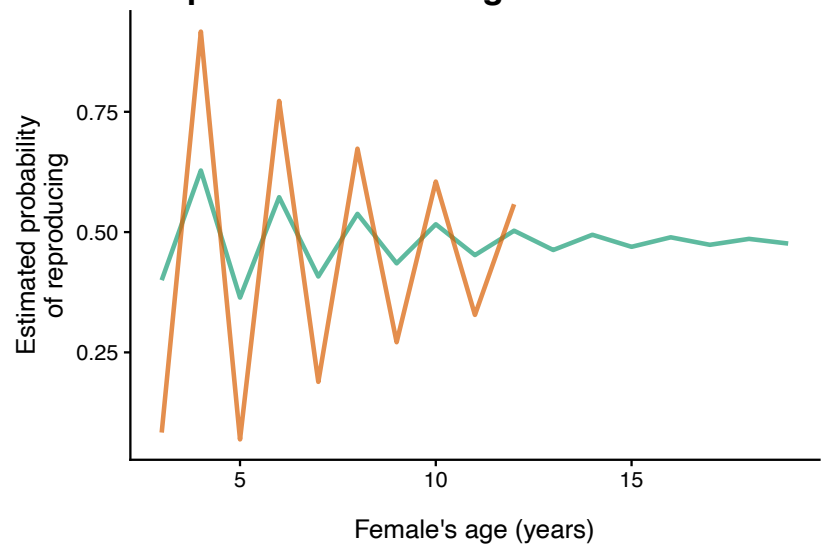

E

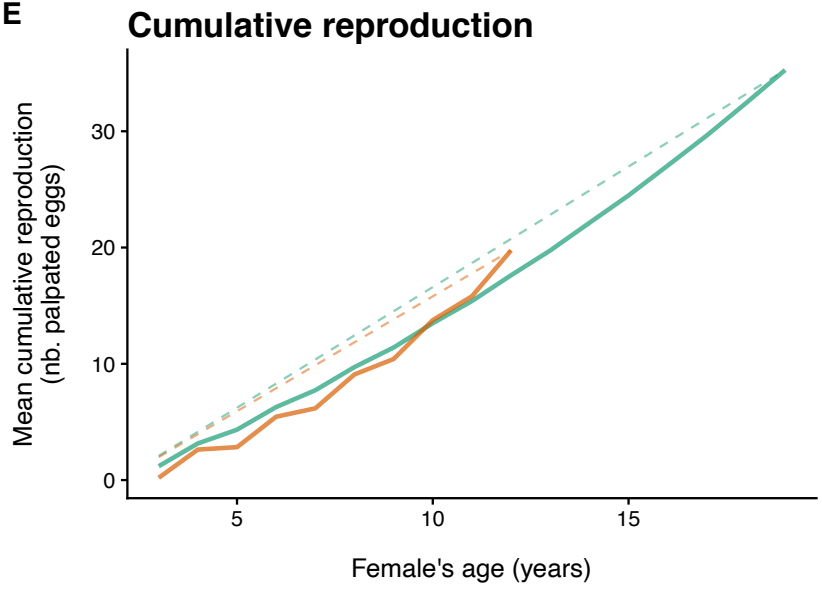

B
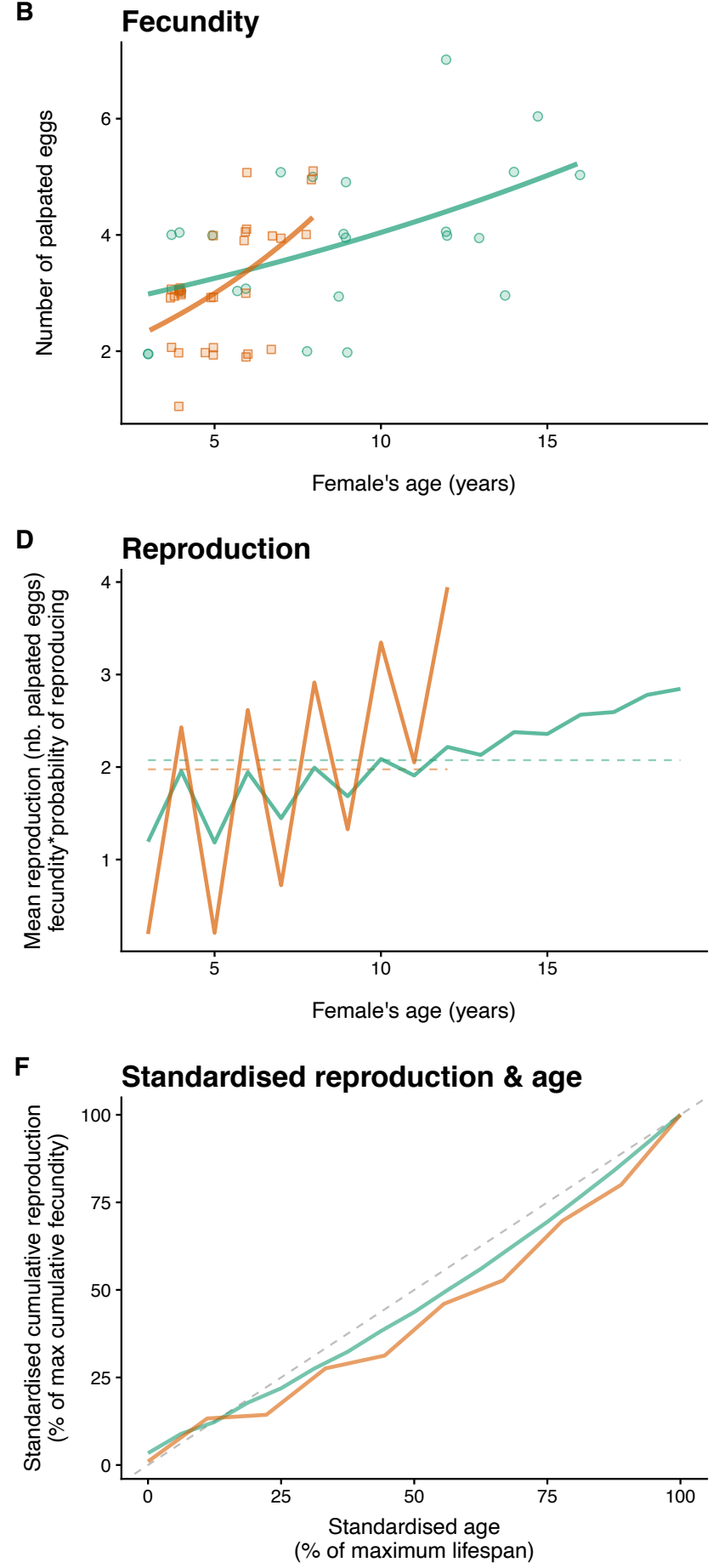

Figure S8: The pace and shape of reproduction following method in Baudisch and Stott (2019). Panel A illustrates the differences in pace of mortality between sexes in the two habitats. The mean life expectancy and $95 \%$ confidence intervals were calculated from the survival curves (dots in Figure $1 \mathrm{~A}$ ). Panel B shows the fecundity of reproducing females as a function of their age and the lines are the predictions from a quasi-poisson model adjusted to raw data (Table S4). The estimated proportion of reproducing females during the reproductive period is plotted on panel C (see method for details). The expected reproduction as a function of age is displayed in panel $D$ and was calculated by multiplying curves from panels $B$ and $C$. The dotted lines represent the mean annual fecundity. The mean cumulative reproduction as a function of age is displayed on panel E. Panel F represents the same data after standardisation of the two axes to better compare the shape of reproduction between the two habitats (Baudisch \& Stott, 2019). The dotted lines represent the expected increase in cumulative reproduction in the case of no senescence. The female maximum lifespans (Figure $1 \mathrm{~A}$ ) are used to estimate the potential reproducing period in each habitat (panels C-F). 


\section{Supporting Information 7 - Reproduction corrected for body length as a function of standardised age}

Figure S9: Reproduction corrected for body length as a function of standardised age. The panel $A$ represents the fecundity (and panel $B$ the reproductive investment) adjusted for female length as a function of standardised age. Standardised age is the female age divided by the life expectancy in each habitat (5.05 years in A and 5.85 years in B). For both traits, neither habitat nor standardised age significantly influenced reproduction adjusted for female length.
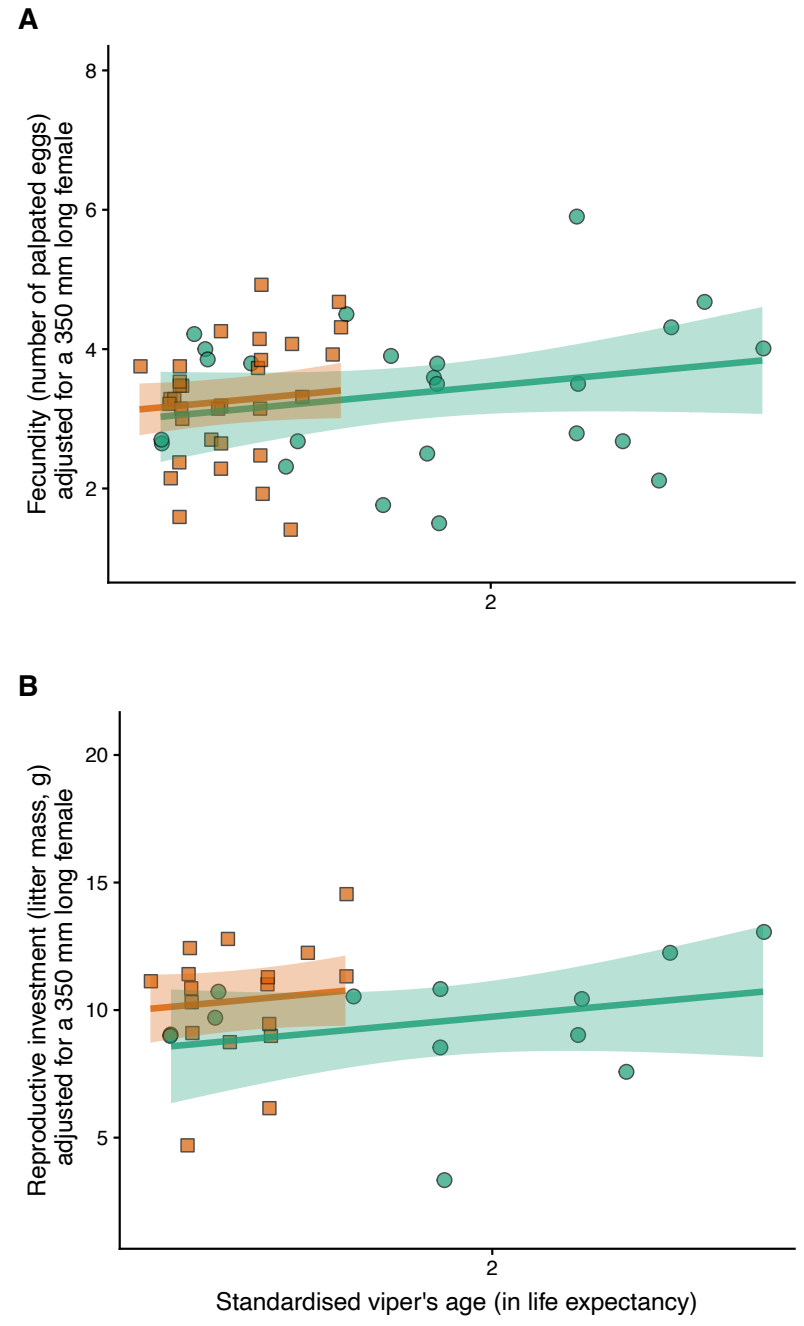

Sex-specific fitness returns are too weak to select for non-random patterns of sex allocation in a viviparous snake. Oecologia, 164(2), 369-378. 10.1007/ s00442-010-1660-y

Baudisch, A. (2008). Inevitable aging? Contributions to evolutionary-demographic theory. Berlin, Heidelberg: Springer.

Baudisch, A. (2011). The pace and shape of ageing. Methods in Ecology and Evolution, 2(4), 375-382. 10.1111/j.2041-210X.2010.00087.x

Baudisch, A., Salguero-Gómez, R., Jones, O. R., Wrycza, T., Mbeau-Ache, C., Franco, M. et al. (2013). The pace and shape of senescence in angiosperms. Journal of Ecology, 101(3), 596-606. 10.1111/1365-2745.12084

Baudisch, A., \& Stott, I. (2019). A pace and shape perspective on fertility. Methods in Ecology and Evolution, 10(11), 1941-1951.

Baudisch, A., \& Vaupel, J. (2010). Senescence vs. sustenance: Evolutionary-demographic models of aging. Demographic Research, 23, 655-668. 10.4054/DemRes.2010.23.23

Blažek, R., Polačik, M., Kačer, P., Cellerino, A.,

Baron, J.-P., Tully, T., \& Le Galliard, J.-F. (2010b). 
Řežucha, R., Methling, C. et al. (2017). Repeated intraspecific divergence in life span and aging of African annual fishes along an aridity gradient. Evolution, 71(2), 386-402. 10.1111/evo.13127

Bonnet, X., Naulleau, G., \& Shine, R. (1999). The dangers of leaving home: dispersal and mortality in snakes. Biological conservation, 89(1), 39-50.

Bouwhuis, S., Charmantier, A., Verhulst, S., \& Sheldon, B. C. (2010). Individual variation in rates of senescence: natal origin effects and disposable soma in a wild bird population. J Anim Ecol, 79(6), 1251-1261. 10.1111/j.1365-2656.2010.01730.x

Bronikowski, A., \& Flatt, T. (2010). Aging and its demographic measurement. Nat. Educ. Knowl, 1(3).

Bronikowski, A. M. (2008). The evolution of aging phenotypes in snakes: a review and synthesis with new data. AGE, 30(2-3), 169-176. 10.1007/ s11357-008-9060-5

Bronikowski, A. M., Alberts, S. C., Altmann, J., Packer, C., Carey, K. D., \& Tatar, M. (2002). The aging baboon: comparative demography in a nonhuman primate. Proceedings of the National Academy of Sciences, 99(14), 9591-9595.

Colchero, F., \& Clark, J. S. (2012). Bayesian inference on age-specific survival for censored and truncated data. J Anim Ecol, 81(1), 139-149. 10.1111/ j.1365-2656.2011.01898.x

Colchero, F., Jones, O. R., \& Rebke, M. (2012). BaSTA: an $R$ package for Bayesian estimation of age-specific survival from incomplete mark-recapture/recovery data with covariates. Methods in Ecology and Evolution, 3(3), 466-470. 10.1111/ j.2041-210X.2012.00186.x

Colchero, F., Rau, R., Jones, O. R., Barthold, J. A., Conde, D. A., Lenart, A. et al. (2016). The emergence of longevous populations. Proceedings of the National Academy of Sciences, 113(48), E7681E7690.

Dupoué, A., Stahlschmidt, Z. R., Michaud, B., \& Lourdais, O. (2015). Physiological state influences evaporative water loss and microclimate preference in the snake Vipera aspis. Physiol Behav, 144, 82-89. 10.1016/j.physbeh.2015.02.042

Dupoué, A., Angelier, F., Brischoux, F., DeNardo, D. F., Trouvé, C., Parenteau, C. et al. (2016). Water deprivation increases maternal corticosterone levels and enhances offspring growth in the snakeVipera aspis. The Journal of Experimental Biology, 219(5), 658-667. 10.1242/jeb.132639

Dupoué, A., Brischoux, F., Angelier, F., DeNardo, D. F., Wright, C. D., \& Lourdais, O. (2015). Intergenerational trade-off for water may induce a motheroffspring conflict in favour of embryos in a viviparous snake. Functional Ecology, 29(3), 414-422. 10.1111/1365-2435.12349

Eckhardt, F., Kappeler, P. M., \& Kraus, C. (2017). Highly variable lifespan in an annual reptile, Labord's chameleon (Furcifer labordi). Sci Rep, 7(1), 11397. 10.1038/s41598-017-11701-3

Finch, C. E. (1998). Variations in Senescence and
Longevity Include the Possibility of Negligible Senescence. The Journals of Gerontology Series A: Biological Sciences and Medical Sciences, 53A(4), B235B239. 10.1093/gerona/53A.4.B235

Finch, C. E. (2009). Update on Slow Aging and Negligible Senescence - A Mini-Review. Gerontology, 55(3), 307-313. 10.1159/000215589

Forsman, A. (1997). Growth and survival of Vipera berus in a variable environment. In R. S. Thorpe, W. Wuster, \& A. Malhotra (Eds.), Venomous Snakes: Ecology, Evolution and Snakebite. Oxford University Press.

French, S. S., Neuman-Lee, L. A., Terletzky, P. A., Kiriazis, N. M., Taylor, E. N., \& DeNardo, D. F. (2017). Too much of a good thing? Human disturbance linked to ecotourism has a "dose-dependent" impact on innate immunity and oxidative stress in marine iguanas, Amblyrhynchus cristatus. Biological conservation, 210, 37-47. 10.1016/ j.biocon.2017.04.006

Hassall, C., Amaro, R., Ondina, P., Outeiro, A., Cordero-Rivera, A., \& San Miguel, E. (2016). Populationlevel variation in senescence suggests an important role for temperature in an endangered mollusc. Journal of Zoology, 301(1), 32-40. 10.1111/jzo.12395

Hayward, A. D., Moorad, J., Regan, C. E., Berenos, C., Pilkington, J. G., Pemberton, J. M. et al. (2015). Asynchrony of senescence among phenotypic traits in a wild mammal population. Experimental gerontology, 71, 56-68.

Holand, H., Kvalnes, T., Gamelon, M., Tufto, J., Jensen, H., Pärn, H. et al. (2016). Spatial variation in senescence rates in a bird metapopulation. Oecologia, 181(3), 865-871. 10.1007/s00442-016-3615-4

Jones, O. R., Scheuerlein, A., Salguero-Gómez, R., Camarda, C. G., Schaible, R., Casper, B. B. et al. (2014). Diversity of ageing across the tree of life. Nature, 505, 169-173. 10.1038/nature12789

Kelly, M. A., Zieba, A. P., Buttemer, W. A., \& Hulbert, A. J. (2013). Effect of temperature on the rate of ageing: an experimental study of the blowfly Calliphora stygia. PLoS One, 8(9), e73781. 10.1371/journal.pone.0073781

Lemaître, J. F., Gaillard, J. M., Lackey, L. B., Clauss, M., \& Müller, D. W. (2013). Comparing free-ranging and captive populations reveals intra-specific variation in aging rates in large herbivores. Exp Gerontol, 48(2), 162-167. 10.1016/j.exger.2012.12.004

Lemaître, J. F., Ronget, V., Tidière, M., Allainé, D., Berger, V., Cohas, A. et al. (2020). Sex differences in adult lifespan and aging rates of mortality across wild mammals. Proc Natl Acad Sci U S A, 117(15), 8546-8553. 10.1073/pnas.1911999117

Lourdais, O., Dupoué, A., Guillon, M., Guiller, G., Michaud, B., \& DeNardo, D. F. (2017). Hydric "Costs" of Reproduction: Pregnancy Increases Evaporative Water Loss in the Snake Vipera aspis. Physiol Biochem Zool, 90(6), 663-672. 10.1086/694848

Madsen, T., Shine, R., Loman, J., \& Håkansson, T. (1993). Determinants of mating success in male ad- 
ders, Vipera berus. Animal Behaviour, 45(3), 491-499.

Mallard, F., Farina, M., \& Tully, T. (2015). Within species variation in long-term trajectories of growth, fecundity and mortality in the Collembola Folsomia candida. Journal of Evolutionary Biology, Epub, 1-9. 10.1111/jeb.12752

Massot, M., Clobert, J., Montes-Poloni, L., Haussy, C., Cubo, J., \& Meylan, S. (2011). An integrative study of ageing in a wild population of common lizards. Functional Ecology, 25(4), 848-858. 10.1111/ j.1365-2435.2011.01837.x

Morbey, Y. E., Brassil, C. E., \& Hendry, A. P. (2005). Rapid senescence in Pacific salmon. The American Naturalist, 166(5), 556-568.

Nussey, D. H., Coulson, T., Festa-Bianchet, M., \& Gaillard, J.-M. (2008). Measuring senescence in wild animal populations: towards a longitudinal approach. Functional Ecology, 22(3), 393-406. 10.1111/ j.1365-2435.2008.01408.x

Nussey, D. H., Kruuk, L. E. B., Morris, A., \& CluttonBrock, T. H. (2007). Environmental conditions in early life influence ageing rates in a wild population of red deer. Current Biology, 17(23), R1000-R1001.

Nussey, D. H., Froy, H., Lemaitre, J. F., Gaillard, J. M., \& Austad, S. N. (2013). Senescence in natural populations of animals: widespread evidence and its implications for bio-gerontology. Ageing Res Rev, 12(1), 214-225. 10.1016/j.arr.2012.07.004

Reichard, M. (2016). Evolutionary ecology of aging: time to reconcile field and laboratory research. Ecol Evol, 6(9), 2988-3000. 10.1002/ece3.2093

Reznick, D. N., Bryant, M. J., Roff, D., Ghalambor, C. K., \& Ghalambor, D. E. (2004). Effect of extrinsic mortality on the evolution of senescence in guppies. Nature, 431(7012), 1095-1099. 10.1038/ nature02936

Rollings, N., Uhrig, E. J., Krohmer, R. W., Waye, H. L., Mason, R. T., Olsson, M. et al. (2017). Age-related sex differences in body condition and telomere dynamics of red-sided garter snakes. Proceedings of the Royal Society B: Biological Sciences, 284(1852), 20162146. 10.1098/rspb.2016.2146

Saint Girons, H. (1957). Croissance et fécondité de Vipera aspis (L). Vie Milieu, 8, 265-286.

Shefferson, R. P., Jones, O. R., \& Salguero-Gómez, R. (2017). The evolution of senescence in the tree of life. Cambridge: Cambridge University Press.

Shine, R. (2003). Reproductive strategies in snakes. Proc Biol Sci, 270(1519), 995-1004. 10.1098/ rspb.2002.2307

Sparkman, A. M., Arnold, S. J., \& Bronikowski, A. M. (2007). An empirical test of evolutionary theories for reproductive senescence and reproductive effort in the garter snake Thamnophis elegans. Proc Biol Sci, 274(1612), 943-950. 10.1098/rspb.2006.0072

Stark, G., Tamar, K., Itescu, Y., Feldman, A., \& Meiri, S. (2018). Cold and isolated ectotherms: drivers of reptilian longevity. Biological Journal of the Linnean Society, 125(4), 730-740.

Stier, A., Dupoué, A., Picard, D., Angelier, F., Brischoux, F., \& Lourdais, O. (2017). Oxidative stress in a capital breeder (Vipera aspis) facing pregnancy and water constraints. The Journal of Experimental Biology, 220(10), 1792-1796. 10.1242/ jeb. 156752

Tatar, M., Chien, S. A., \& Priest, N. K. (2001). Negligible senescence during reproductive dormancy in Drosophila melanogaster. The American Naturalist, 158(3), 248-258.

Tully, T., Le Galliard, J.-F., \& Baron, J.-P. (2020). Dataset on the reproductive and actuarial ageing in a population of meadow vipers (Vipera ursinii) in the Mont Serein (France). Zenodo. 10.5281/zenodo.3900150

Joger, U., Isailovic, J. C., Vogrin, M., Corti, C., Sterijovski, B., Westerström, A. et al. (2009). Vipera ursinii. The IUCN Red List of Threatened Species. http:/ /dx.doi.org/10.2305/

IUCN.UK.2009.RLTS.T22997A9406628.en

Vaupel, J. W., Carey, J. R., \& Christensen, K. (2003). Its never too late. Science (New York, NY), 301(5640), 1679.

Vaupel, J. W., Baudisch, A., Dölling, M., A. Roach, D., \& Gampe, J. (2004). The case for negative senescence. Theoretical Population Biology, 65(4), 339-351. 10.1016/j.tpb.2003.12.003

Wensink, M. J., Caswell, H., \& Baudisch, A. (2017). The rarity of survival to old age does not drive the evolution of senescence. Evolutionary biology, 44(1), 5-10. 10.1007/s11692-016-9385-4

Wensink, M. J., van Heemst, D., Rozing, M. P., \& Westendorp, R. G. J. (2012). The maintenance gap: a new theoretical perspective on the evolution of aging. Biogerontology, 13(2), 197-201. 10.1007/ s10522-011-9362-3

Wrycza, T. F., Missov, T. I., \& Baudisch, A. (2015). Quantifying the Shape of Aging. PLOS ONE, 10(3), e0119163. 10.1371/journal.pone.0119163 